\title{
Preliminary Feasibility Assessment of Integrating CCHP with NW Food Processing Plant \#1: Modeling Documentation
}
MG Hoffman
A Makhmalbaf
$\checkmark$ Srivastava
JA Thornton ${ }^{1}$
AW Wagner

January 2014

\section{Pacific Northwest}

NATIONAL LABORATORY

Northwest Food Processors Association

Proudly Operated by Battelle Since 1965 



\title{
DISCLAIMER
}

This report was prepared as an account of work sponsored by an agency of the United States Government. Neither the United States Government nor any agency thereof, nor Battelle Memorial Institute, nor any of their employees, makes any warranty, express or implied, or assumes any legal liability or responsibility for the accuracy, completeness, or usefulness of any information, apparatus, product, or process disclosed, or represents that its use would not infringe privately owned rights. Reference herein to any specific commercial product, process, or service by trade name, trademark, manufacturer, or otherwise does not necessarily constitute or imply its endorsement, recommendation, or favoring by the United States Government or any agency thereof, or Battelle Memorial Institute. The views and opinions of authors expressed herein do not necessarily state or reflect those of the United States Government or any agency thereof.

\author{
PACIFIC NORTHWEST NATIONAL LABORATORY \\ operated by \\ BATTELLE \\ for the \\ UNITED STATES DEPARTMENT OF ENERGY \\ under Contract DE-AC05-76RL01830
}

Printed in the United States of America
Available to DOE and DOE contractors from the Office of Scientific and Technical Information,
P.O. Box 62, Oak Ridge, TN 37831-0062;
ph: (865) 576-8401
fax: $(865) 576-5728$
email: reports@adonis.osti.gov

\footnotetext{
Available to the public from the National Technical Information Service, U.S. Department of Commerce, 5285 Port Royal Rd., Springfield, VA 22161 ph: (800) 553-6847 fax: $(703) 605-6900$ email: orders@ntis.fedworld.gov online ordering: http://www.ntis.gov/ordering.htm
}

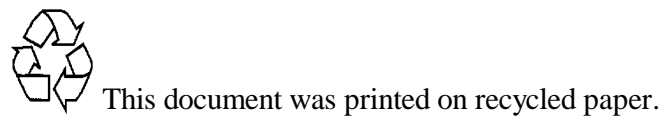





\section{Preliminary Feasibility Assessment of Integrating CCHP with NW Food Processing Plant \#1: Modeling Documentation}

MG Hoffman

V Srivastava

January 2014
A Makhmalbaf

AW Wagner

Prepared for

the U.S. Department of Energy

under Contract DE-AC05-76RL01830

and for the Bonneville Power Administration

and the Northwest Food Processors Association

under Award Number 54177-5

Pacific Northwest National Laboratory

Richland, Washington 99352 



\section{Summary}

This documentation has been prepared to support the spreadsheet-based model constructed to calculate energy, emissions, and cost savings achieved by using combined cooling, heating, and electric power (CCHP) at food processing Plant \#1 located in Portland, Oregon. Because of a confidentiality agreement with the Northwest Food Processors Association (NWFPA), this plant is not identified specifically.

This documentation includes the following:

1. an overview of the plant, including:
a. type of operation
b. location
c. energy requirements
d. current system characteristics
e. power quality and reliability information

2. energy costs
a. utility serving the plant
i. cost of electricity
ii. cost of electricity for the utility to serve the plant
b. current cost of electricity for the plant

3. CCHP equipment selection and sizing

4. modeling approach

5. feasibility analysis.

Evaluation of opportunities for cost savings and emissions reductions are included in addition to an energy assessment of the plant. 


\section{Acknowledgements}

We extend appreciation to Ron Sporseen and Allen Burns of PK Energy for their support. We also thank Donald Erickson and Ellen Makar of Energy Concepts. 


\title{
Abbreviations and Definitions
}

\author{
AHP \\ absorption heat pump \\ BPA \\ Bonneville Power Administration \\ Btu \\ British thermal unit - unit of energy \\ CCHP \\ combined cooling, heat and electric power \\ CHP \\ combined heat and power \\ COP \\ coefficient of performance \\ demand \\ amount of energy needed by end uses \\ DG \\ DOE \\ distributed generation, which refers to any on-site power generation system \\ ESS \\ heat pump \\ hp \\ U.S. Department of Energy \\ energy storage system \\ a device designed to provide both heating and cooling by reversing the \\ refrigeration cycle \\ INL \\ horsepower \\ $\mathrm{kWh}$ \\ Idaho National Laboratory \\ kilowatt hour(s) - unit of energy \\ MMBtu \\ million Btu \\ MTU \\ MTU Onsite Energy System \\ MW \\ megawatt(s) \\ “Non-wires" solutions \\ Non-wires solutions comprise a broad array of alternatives to delay or eliminate \\ the need for upgrades to the transmission system, including demand response, \\ distributed generation, energy efficiency measures, generation siting, and \\ pricing strategies. \\ NW \\ Northwest (U.S. Pacific) \\ NWFPA \\ Northwest Food Processors Association \\ peak time \\ time of peak electricity use in a day, month, or year \\ PGE \\ Portland General Electric \\ PNNL \\ Pacific Northwest National Laboratory \\ Ton \\ Ton of Refrigeration \\ T\&D system \\ power transmission and distribution system \\ UPS System \\ uninterruptible power supply system \\ represents plant natural gas demand or associated cost \\ represents plant electricity demand or associated cost \\ represents natural gas demand after CCHP integration \\ represents electrical demand after CCHP integration \\ represents cost of CCHP generation (not including cost of fuel)





\section{Contents}

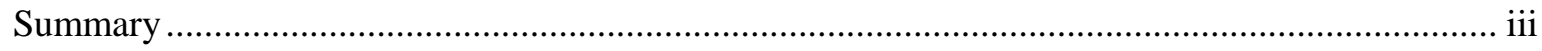

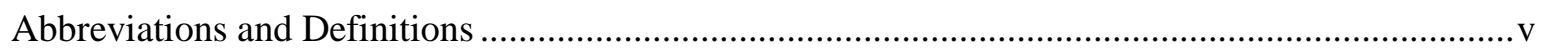

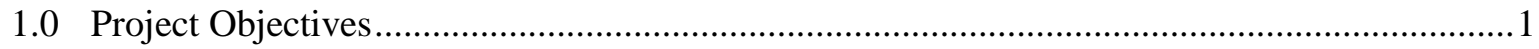

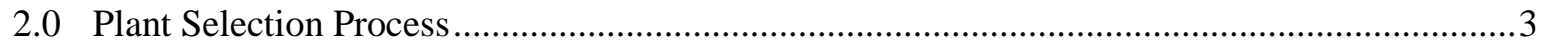

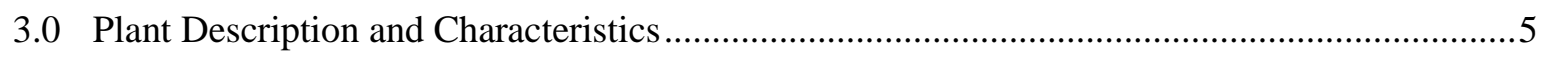

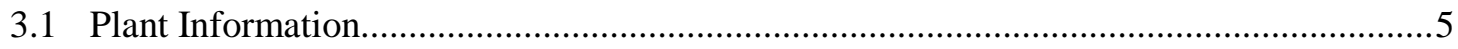

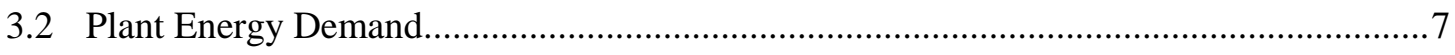

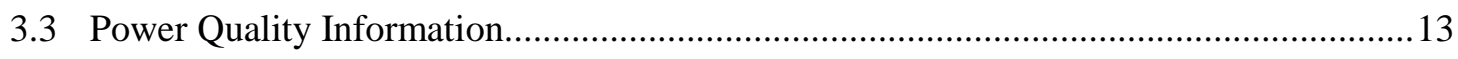

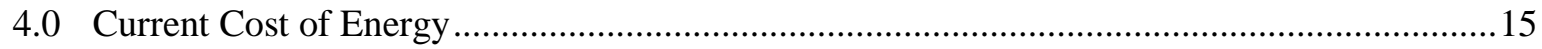

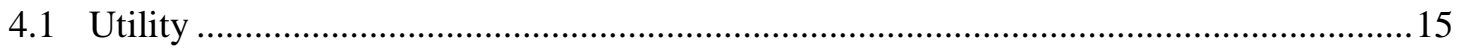

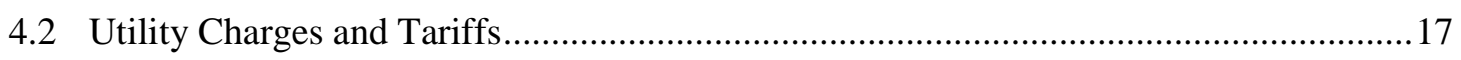

4.3 Monthly Cost of Electricity for the Utility to Serve the Plant.........................................17

4.4 Benefits of Integrated CCHP for the Utility ..................................................................19

4.5 Historic and Current Cost of Energy Purchased by Plant \#1 .........................................20

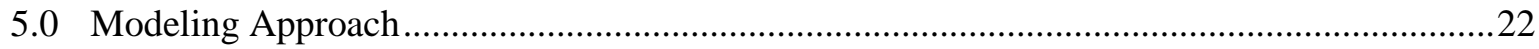

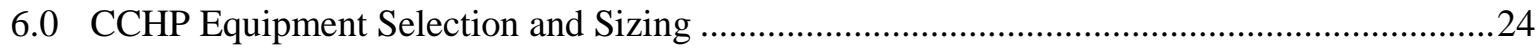

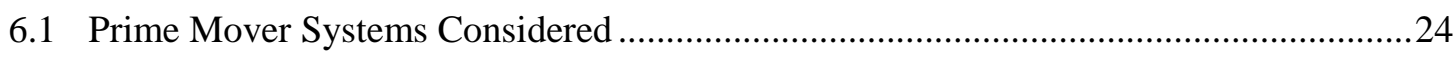

6.2 Absorption Heat Pump Technology ………................................................................25

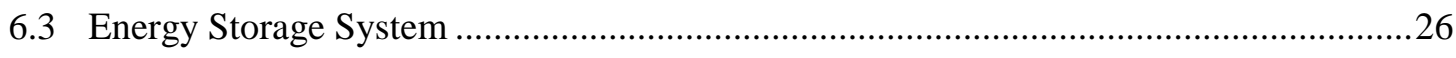

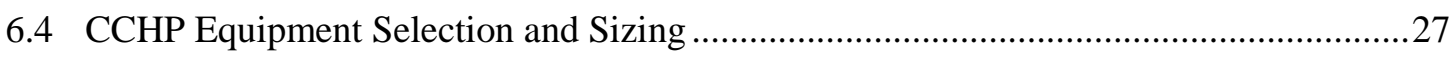

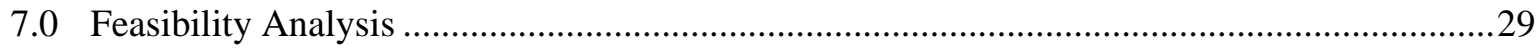

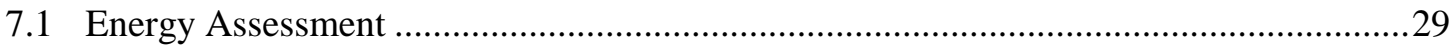

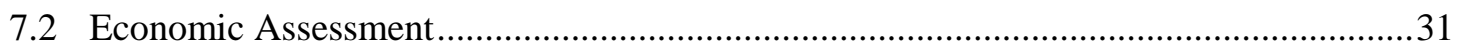

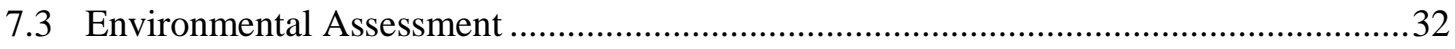

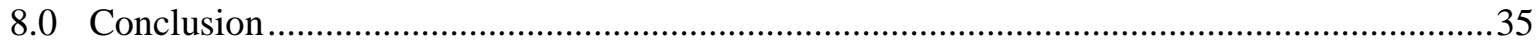

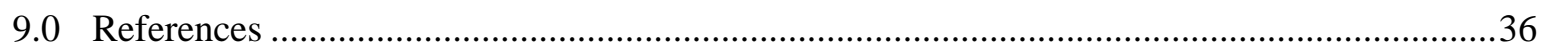




\subsection{Project Objectives}

The Pacific Northwest National Laboratory (PNNL) has launched a project funded by the Bonneville Power Administration (BPA) to identify strategies for increasing industrial energy efficiency and reducing energy costs associated with the Northwest Food Processors Association (NWFPA) industrial plants through deployment of novel combinations and designs of variable-output combined heat and power (CHP) distributed generation (DG), combined cooling, heating and electric power (CCHP) DG and energy storage systems (ESS). CHP DG systems can provide electricity and heat to buildings and industrial processes while significantly reducing energy consumption and emissions. CCHP DG systems can convert unused heat from the DG system into cooling/refrigeration with an absorption heat pump. Additional benefits from such systems include a reduction in the risk of electric grid disruptions, enhancement of energy reliability, reduction in loss of product caused by electric grid disruptions and the cost of insurance for such product loss.

In this project, detailed evaluations and recommendations of CHP and CCHP DG systems will be performed for several Northwest (NW) food processing sites. The objective of this project is to support the goals of the memorandum of understanding between BPA, NWFPA, U.S. Department of Energy (DOE), and DOE National Laboratories - PNNL and Idaho National Laboratory (INL), which are to reduce the overall energy use intensity of NW food processors by $25 \%$ by 2020 and by $50 \%$ by 2030, as well as reducing emissions and understanding potential congestion reduction impacts on the transmission system in the Pacific Northwest. This includes identifying the most viable and effective opportunities for energy efficiency in the food processing industry.

This project also addresses BPA's need for “non-wires” solutions and the associated benefits (ref. BPA 2012). BPA is the primary owner and operator of electricity transmission systems in the Pacific Northwest. BPA started investigating non-wires solutions activities in 2001 and has been supporting them since then as an alternative to large construction projects to expand transmission lines. Penetration of DG is among non-wires solutions considered by BPA to address load growth and congestion on the transmission system.

In Figure 1, a quote from Elliot Mainzer ${ }^{1}$ is documented to highlight the necessity for demand response and energy storage systems for the utility providers.

The target audience for this project includes any stakeholders that have the potential to take advantage of CCHP systems and on-site generation.

\footnotetext{
${ }^{1}$ Elliot Mainzer, Administrator, Bonneville Power Administration.
} 
Elliot Mainzer giving a key note speech on demand response at an EUCI conference last month:

The hydro system has been stretched to its physical margin," Mainzer said. "Our task is to bring new and cost-effective, flexible capacity from outside of the hydro system."

Part of Mainzer's message was that demand response and energy storage can help utilities address their requirements to shave peak and defer infrastructure investments, as well as help the region reduce the need to build transmission and integrate the large amount of renewable energy in the Pacific Northwest.

Mainzer offered suggestions for moving forward by outlining the importance of determining supply curves; defining how reliable and dispatchable the DR tools are; and figuring out the physical and contractual capabilities, as well as how BPA will interface with utilities.

He also committed BPA to doing its part. "Demand response is a real opportunity, and BPA is mobilized to test and demonstrate it."

Figure 1. Quote from Elliot Mainzer presented at the Pacific Northwest Demand Response Project Meeting, January 23, 2014, Northwest Power and Conservation Council Offices, Portland, Oregon. $^{2}$

${ }^{2}$ Available at http://www.nwcouncil.org/energy/dr/meetings/2014_01/ 


\subsection{Plant Selection Process}

There are one hundred and forty NWFPA members and over five hundred and fifty food processors in the Pacific Northwest. One hundred thirty NWFPA plants were identified as potential candidate plants to study the feasibility of integrating CCHP systems. These were down-selected to select the plant for this study. Specific steps are described below.

1. Data was obtained from NWFPA plants as follows:

a. Plant identifications and North American Industry Classification System (NAICS) codes were obtained for 130 plants.

b. The annual energy use (including monthly energy use) in 2011 for electricity and gas was obtained for 67 sites. Production data was also obtained. For some plants, monthly data was not available.

c. In cases where only annual data was available, seasonality (annual, seasonal) is noted based on the type of plant. Monthly data was estimated using similar plants as references.

d. Percentage of electric demand and percentage of natural gas demand were derived.

e. The utility and type (public or investor owned) was documented for the plants.

2. A survey was administered to the 130 NWFPA plants identified as well as additional plants with the objective of increasing the number of potential candidate plants.

a. Number sent: 196; No response: 166; Responded: 30 (15\%); Partial/complete: 8/22; Opted Out: 0; Bounced: 4

3. Other related information was analyzed:

a. Relative cut plane location was identified.

b. Geographic Information System maps for the region that include information on the flow gates areas showing less than 1 megawatt (MW), 1-5 MW, $5 \mathrm{MW}+$ were examined.

4. Eight sites were down-selected:

a. The electricity and natural gas data for 2011 was used to identify the plants with highest energy use; 40 sites with highest annual electricity use for 2011 were selected (Figure 2 and Figure 3).

b. Plants that receive steam or hot water from a utility provider were not selected because the payback from installing a CHP system would be higher for facilities not already using such centralized systems.

c. Monthly electric and gas use data for 2011 for the remaining plants was examined and was found to fall into three categories - seasonal, constant low (relative to other plants), and constant high (relative to other plants) with reduced energy use in July (for constant high plants) (Figure 4 and Figure 5).

d. Plants with high seasonal energy use are not good candidates for CHP and were therefore not selected.

e. Of the remaining plants, four were selected in the constant high category, three were selected in the constant low category, and one was between high and low.

f. The facility designated in this report as Plant \#1 was selected to be the first plant to be studied. 


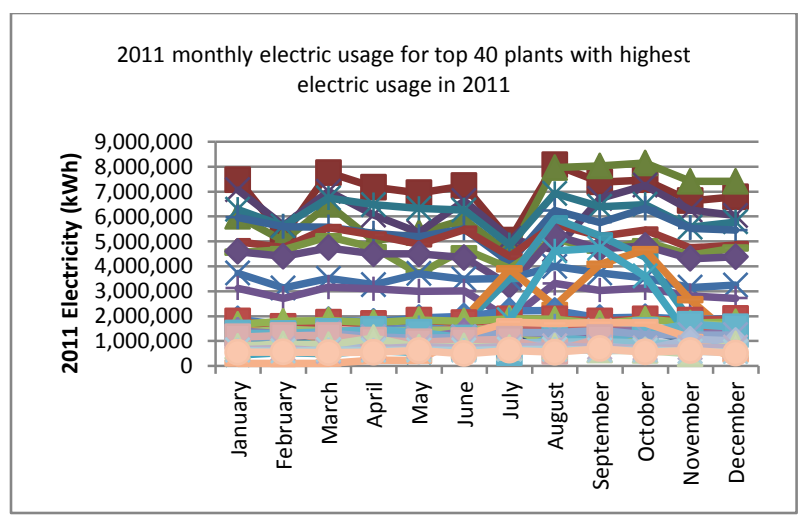

Figure 2. 2011 monthly electricity usage for top 40 plants with highest electricity usage in 2011

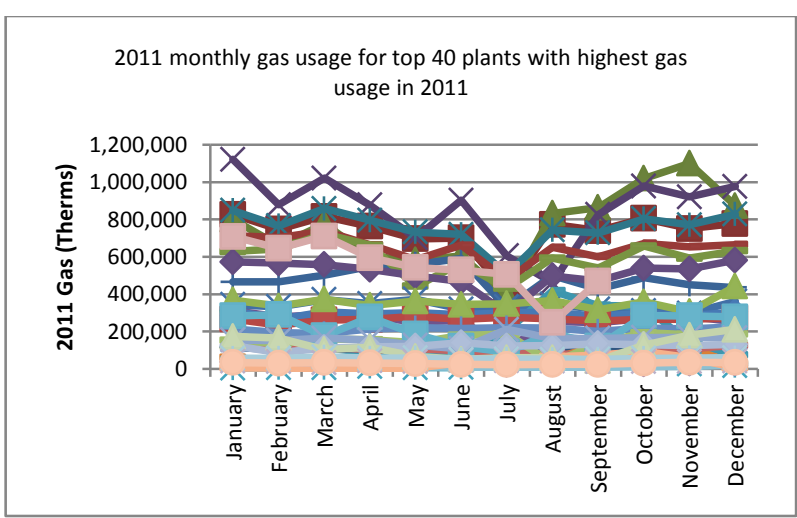

Figure 3. 2011 monthly gas usage for top 40 plants with highest gas usage in 2011

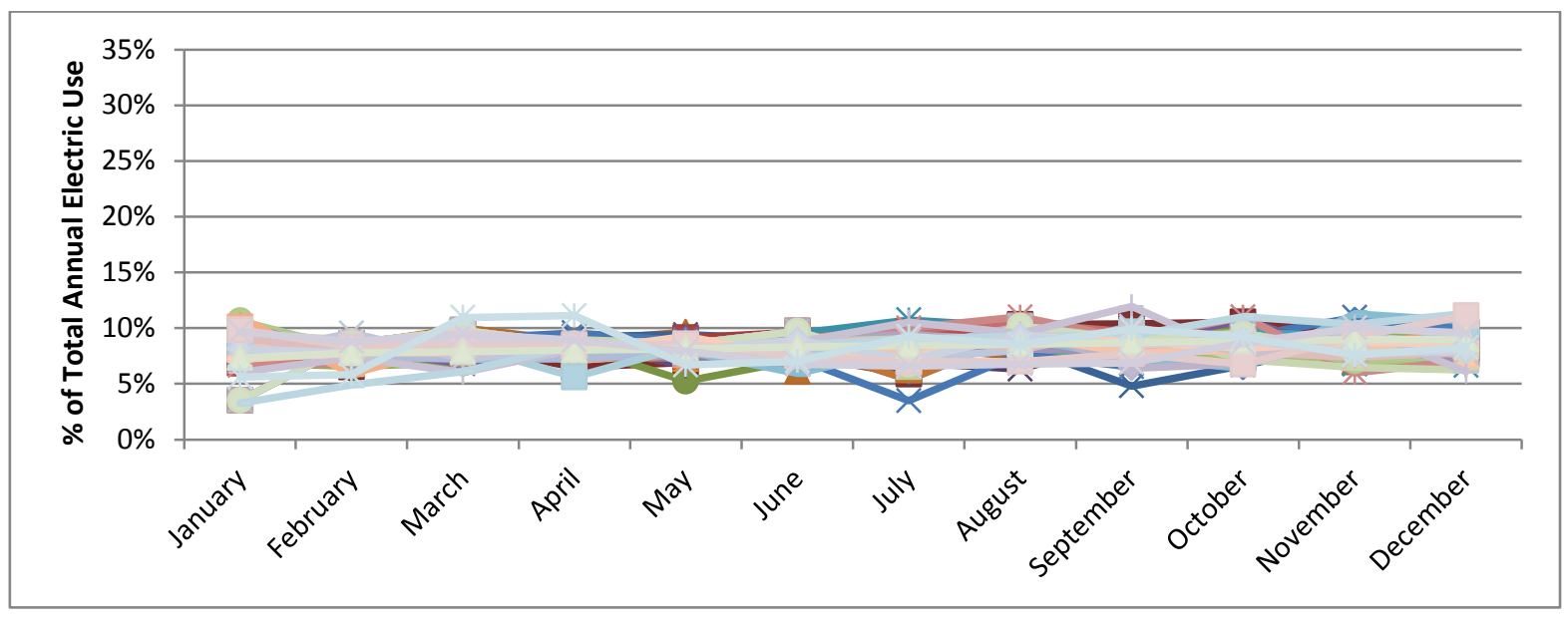

Figure 4. Monthly percent of annual electricity use for “24/7” plants

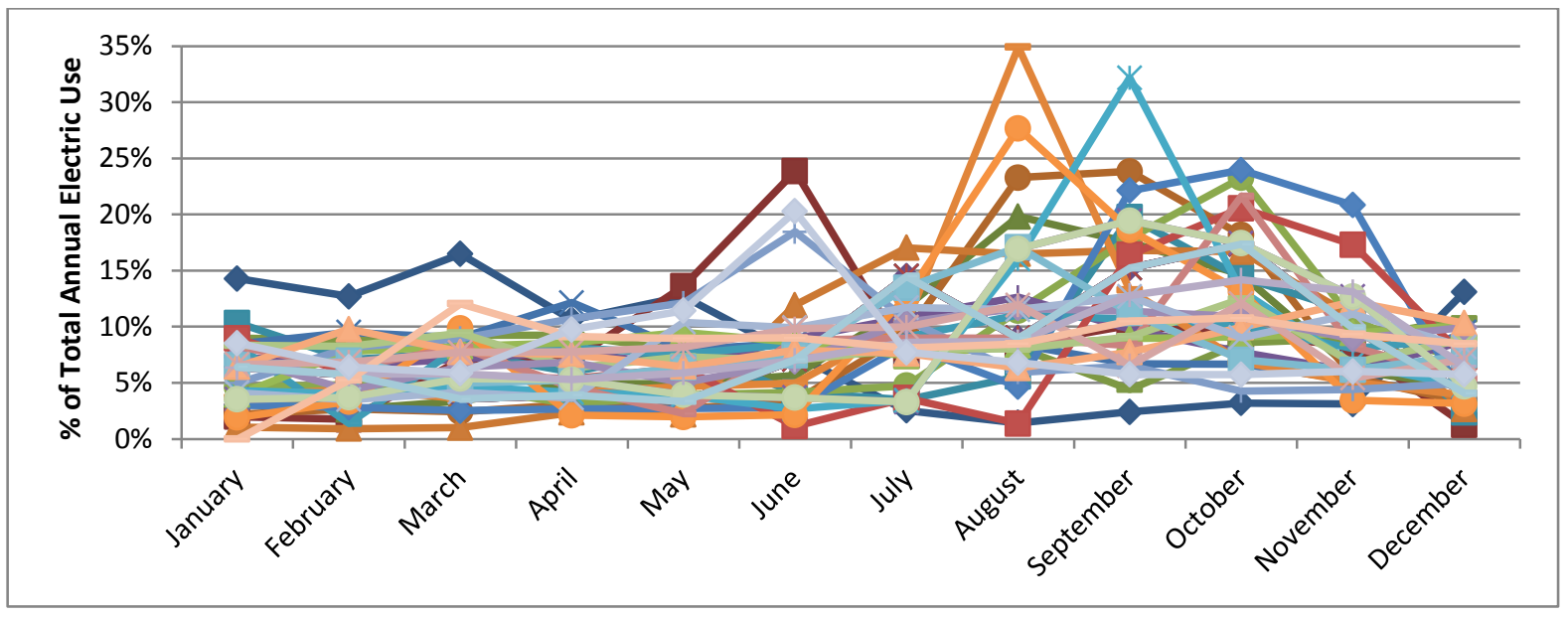

Figure 5. Monthly percent of annual electric use for "peaking” plants 


\subsection{Plant Description and Characteristics}

\subsection{Plant Information}

Key attributes of Plant \#1 are shown in Table 1.

Table 1. Summary of plant information.

\begin{tabular}{|c|c|}
\hline Name & Plant \#1 (This is the plant selected to be the first modeled) \\
\hline Type & Dairy Processing \\
\hline Location & Portland Metro Area, OR \\
\hline Schedule & The facility operates 24 hours per day and 363 days per year. \\
\hline Energy users & $\begin{array}{l}\text { Refrigeration (compressors, condensers, evaporators), compressed air demand-side } \\
\text { followed by pumps, production, lights, heating, ventilating, and air conditioning, and } \\
\text { plug loads }\end{array}$ \\
\hline $\begin{array}{l}\text { Heating and cooling } \\
\text { suppliers }\end{array}$ & $\begin{array}{l}\text { Plant processes are served by direct ammonia, } 28-30^{\circ} \mathrm{F} \text { glycol, } 38^{\circ} \mathrm{F} \text { chilled water, } \\
60^{\circ} \mathrm{F} \text { city water and } 70-80^{\circ} \mathrm{F} \text { tower water. }\end{array}$ \\
\hline $\begin{array}{l}\text { Electrical requirement for } \\
\text { the facility }\end{array}$ & $\begin{array}{l}\text { - } \quad \text { Estimated Average: } 1,714 \mathrm{~kW} \\
\text { - } \quad \text { Peak Load: } 3,121 \mathrm{~kW} \\
\text { - } \quad \text { Annual Usage: } 15,011,600 \mathrm{kWh}\end{array}$ \\
\hline $\begin{array}{l}\text { Heat requirement for the } \\
\text { facility }\end{array}$ & $\begin{array}{l}\text { - The facility has two pasteurizers using directly injected steam to heat the milk. } \\
\text { - Hot water is produced at } 260 \text { gallons/minute at } 160^{\circ} \mathrm{F} \text {. Hot water storage capacity } \\
\text { is } 12,000 \text { gallons. }\end{array}$ \\
\hline $\begin{array}{l}\text { Cooling requirement for } \\
\text { the facility }\end{array}$ & $\begin{array}{l}\text { - Ammonia vapor-compression refrigeration system to cool two glycol chillers, } \\
\text { cold storage warehouse, and chilled water supply } \\
\text { Four rotary screw compressors ( } 350 \mathrm{hp}, 600 \mathrm{hp}, 350 \mathrm{hp} \text { variable frequency drive, } \\
350 \mathrm{hp} \text { ) } \\
100 \text { ton installed capacity, } 50 \text { ton average load, coefficient of performance } \\
\text { (COP) } 3 \\
\text { - Temperature requirement by plant processes: } 33^{\circ} \mathrm{F} \text { to } 39^{\circ} \mathrm{F} \\
\text { - } \quad \text { Cold storage warehouse is held at a temperature of } 40^{\circ} \mathrm{F} \text { to } 42^{\circ} \mathrm{F} \text {. }\end{array}$ \\
\hline
\end{tabular}


Plant \#1 is a dairy processing plant producing a variety of liquid milk products with different flavors and fat percent levels. The generic process diagram for ultra-high temperature fluid milk processing is shown in Figure 6.

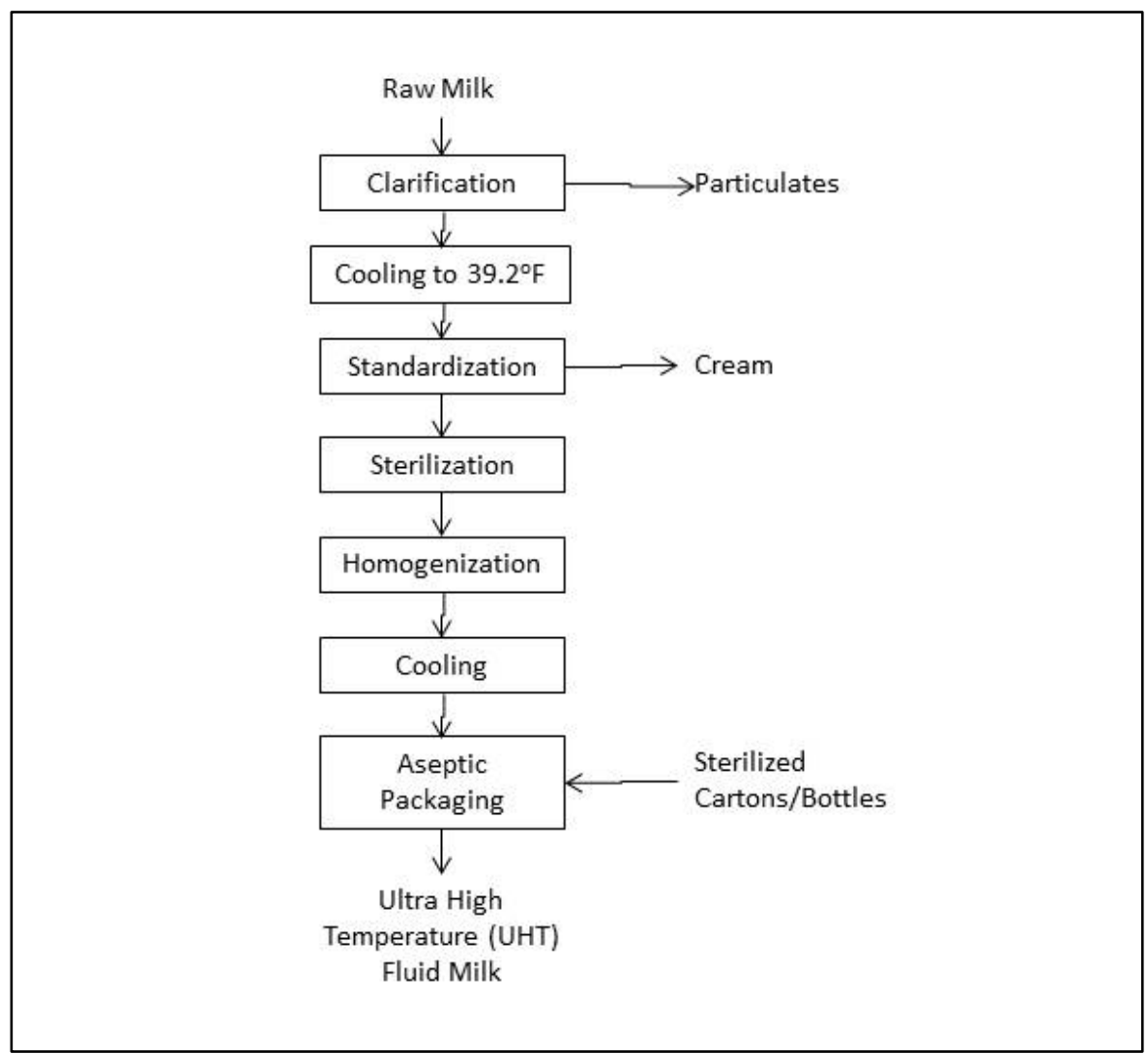

Figure 6. Generic process diagram for ultra-high temperature fluid milk production (Source: Brush et al. 2011) 


\subsection{Plant Energy Demand}

Analysis of plant energy use data indicates that there is a coincident demand for electricity and natural gas as seen in Figures 7 and 10. In addition, the electric demand over the year is relatively constant with use for each month being between $7.1 \%$ and $9.2 \%$ of the annual total, and natural gas demand being between 6.5\% and 9.2\% of the annual total as seen in Figure 7 and Figure 10. Histograms for 2012 electricity and natural gas purchased from the utilities are shown in Figure 8 and Figure 11. A breakdown of the plant electrical load by type of use is shown in Figure 9.

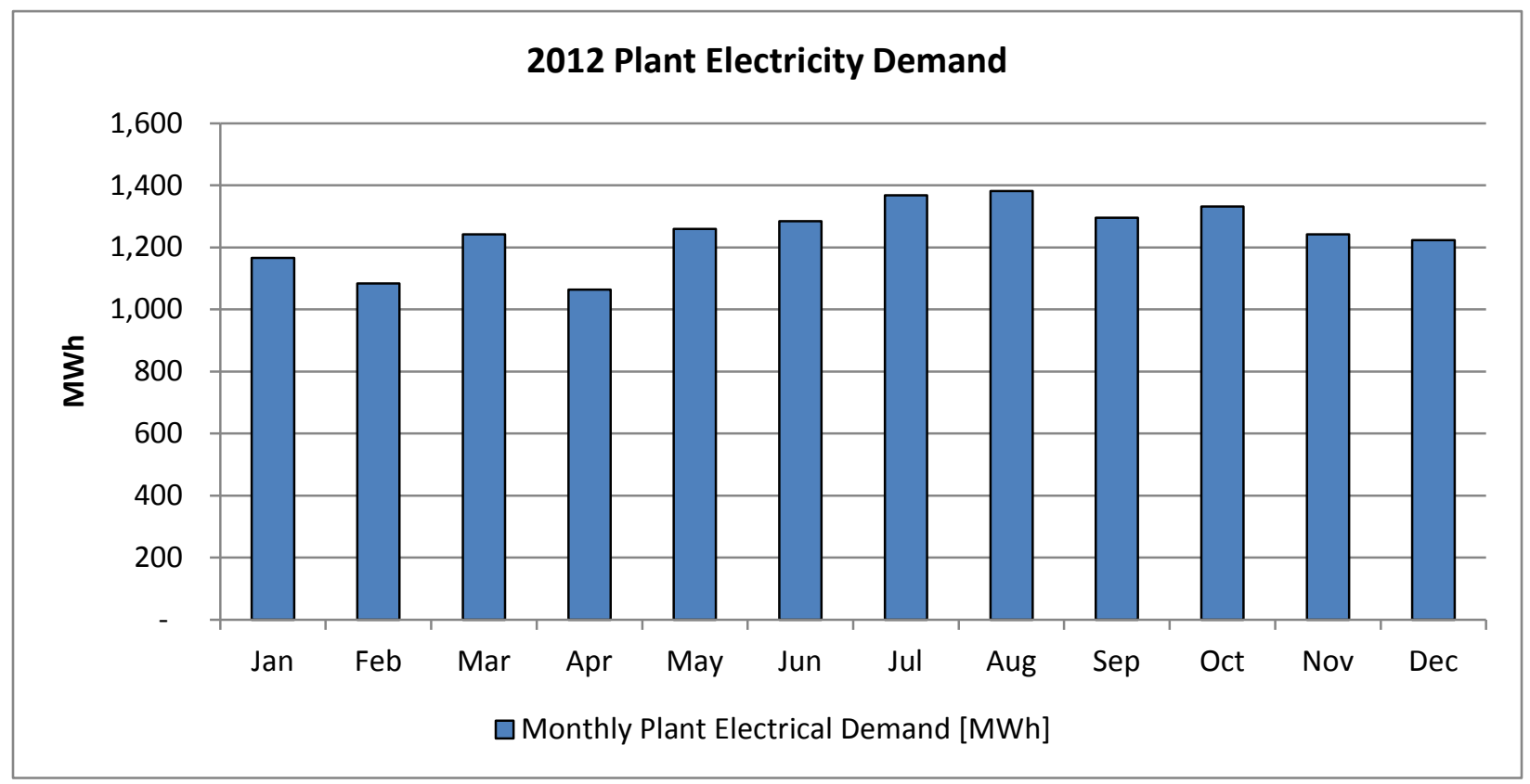

Figure 7. Plant monthly electrical demand in 2012 (total 14,943 MWh)

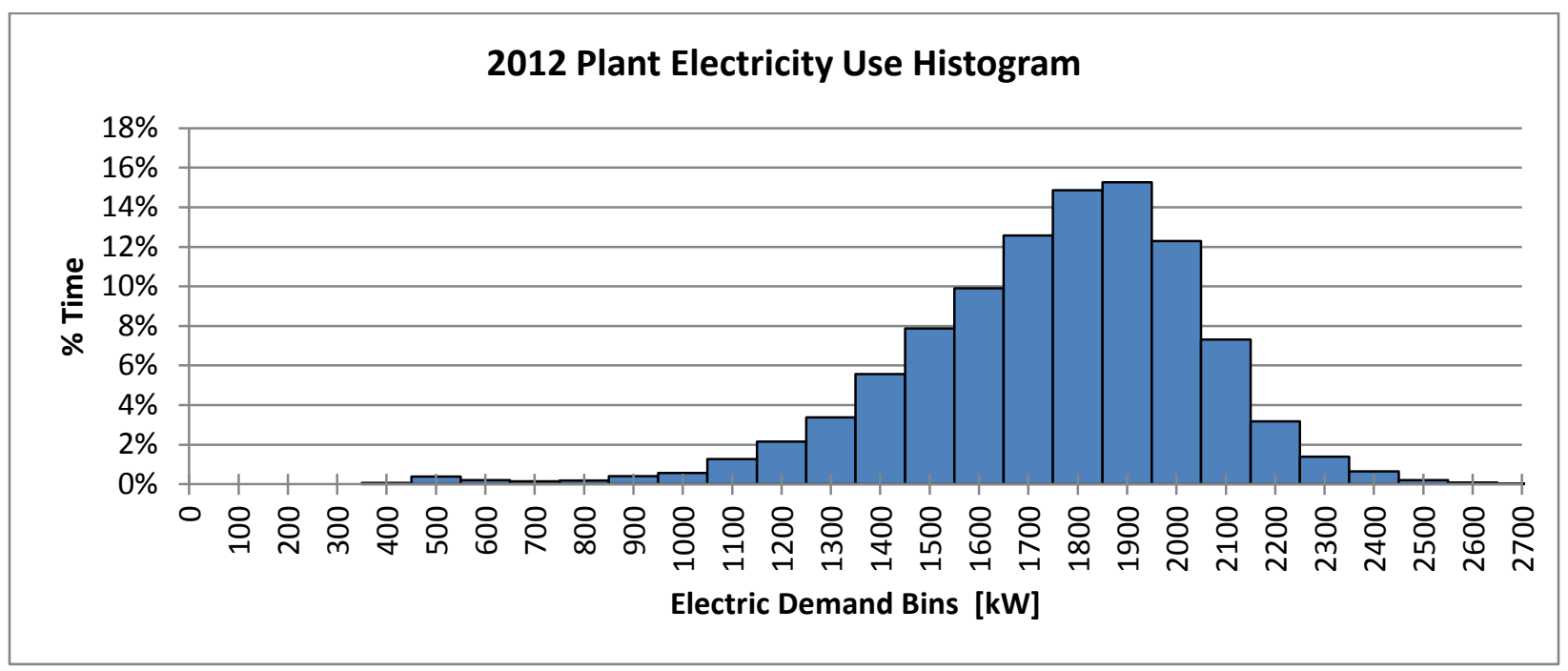

Figure 8. Histogram of electricity use in 2012; 65\% of the time, the demand is between 1500 and $2000 \mathrm{~kW}$. 


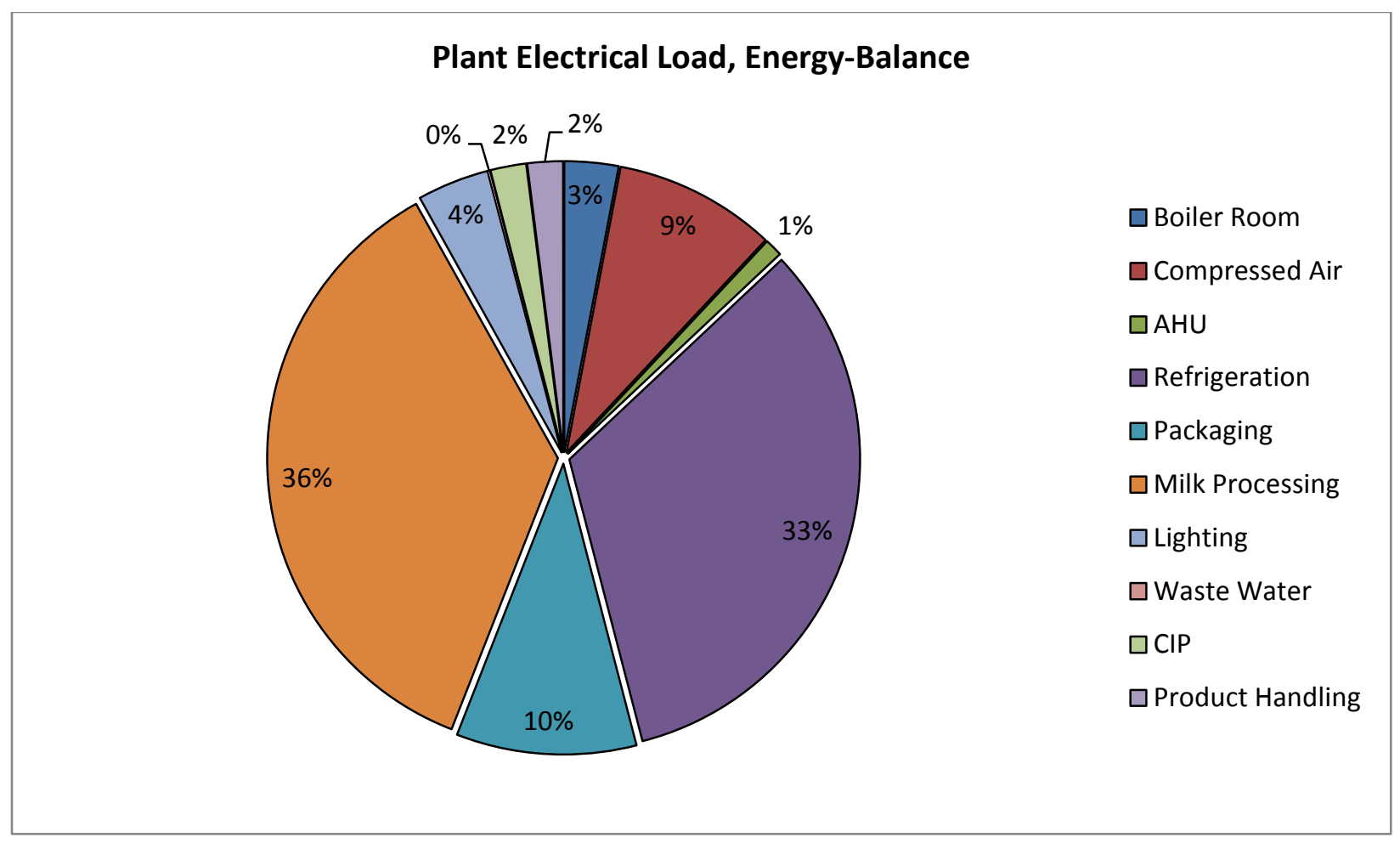

Figure 9. Electrical load distribution in the plant (Source: Engineer at the plant)

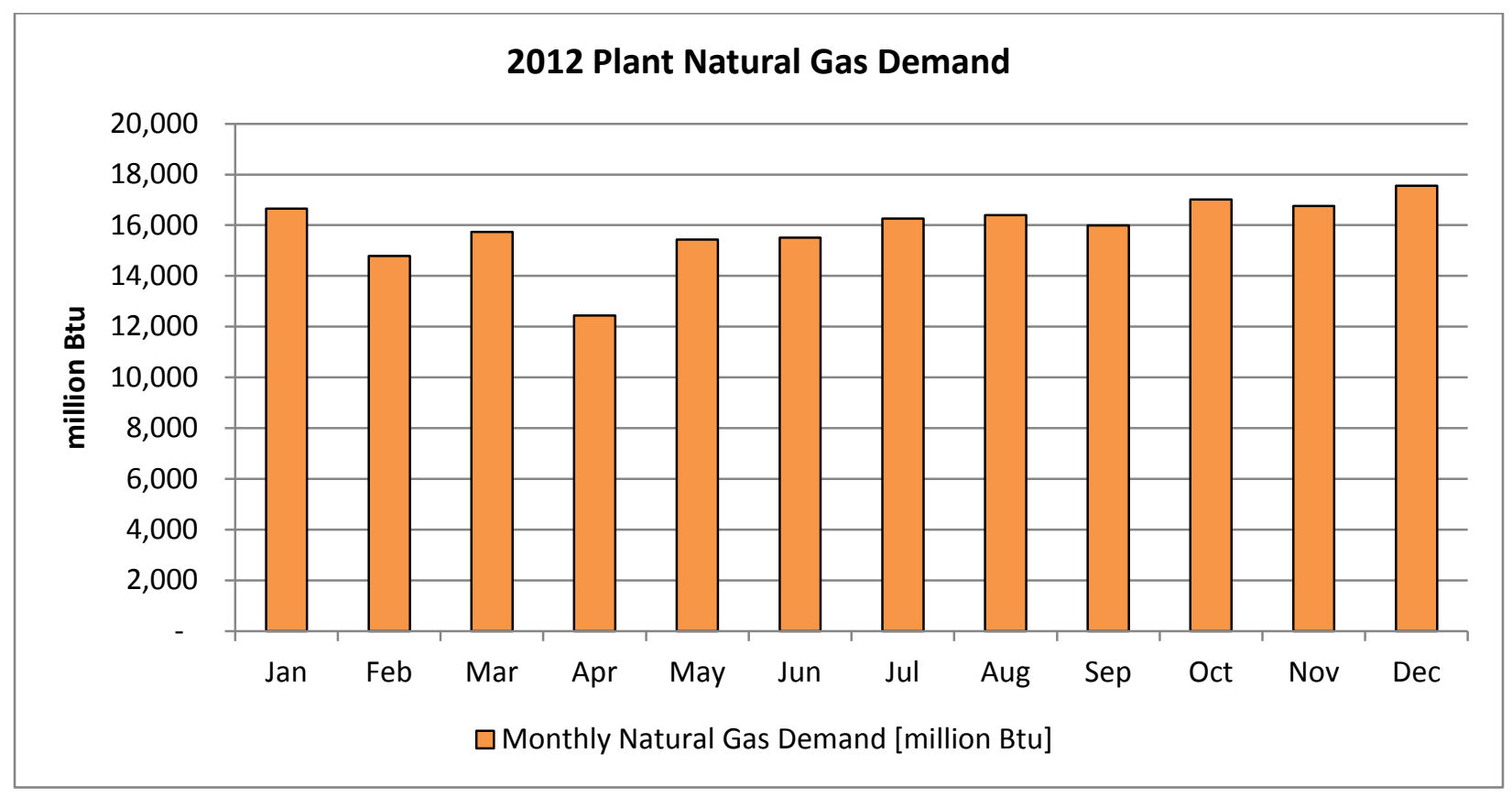

Figure 10. Plant monthly gas demand in 2012 (total 190,569 MMBtu) 


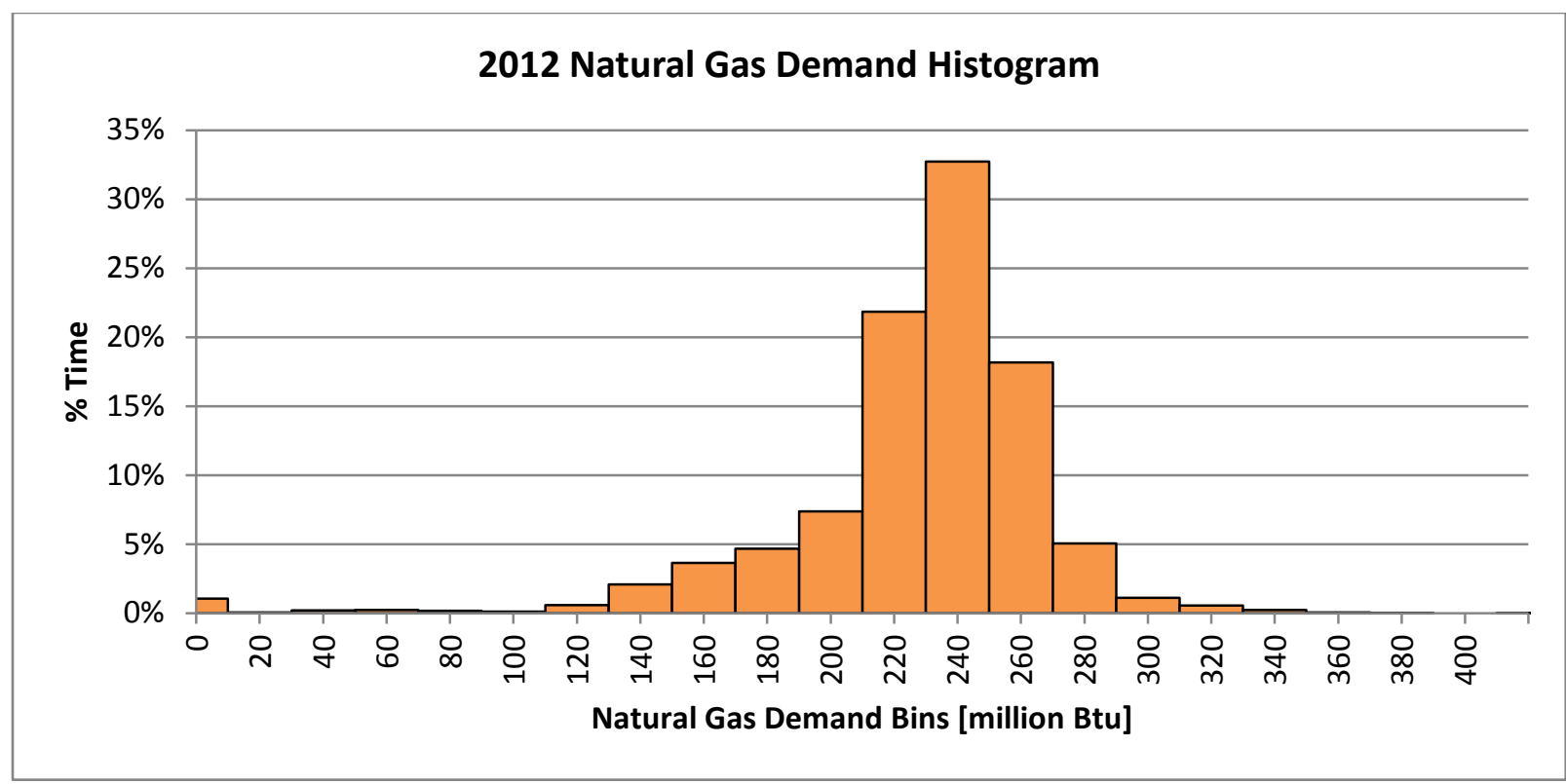

Figure 11. Histogram of natural gas use in 2012; 73\% of the time, the demand is between 20 and 26 MMBtu (200 and 260 therms).

Figure 12 and Figure 13 show comparisons of the electricity and natural gas to be purchased from the utility to operate the plant before and after the integration of a 1.1 MW CCHP system. The peak electricity demand is reduced by a factor of five (2.50 MW to $0.53 \mathrm{MW}$ ) assuming that the electric refrigeration system is replaced by an engine-exhaust-heat driven absorption heat pump. There is an overall increase of 34\% in the natural gas to be purchased from the utility to operate the CCHP system.

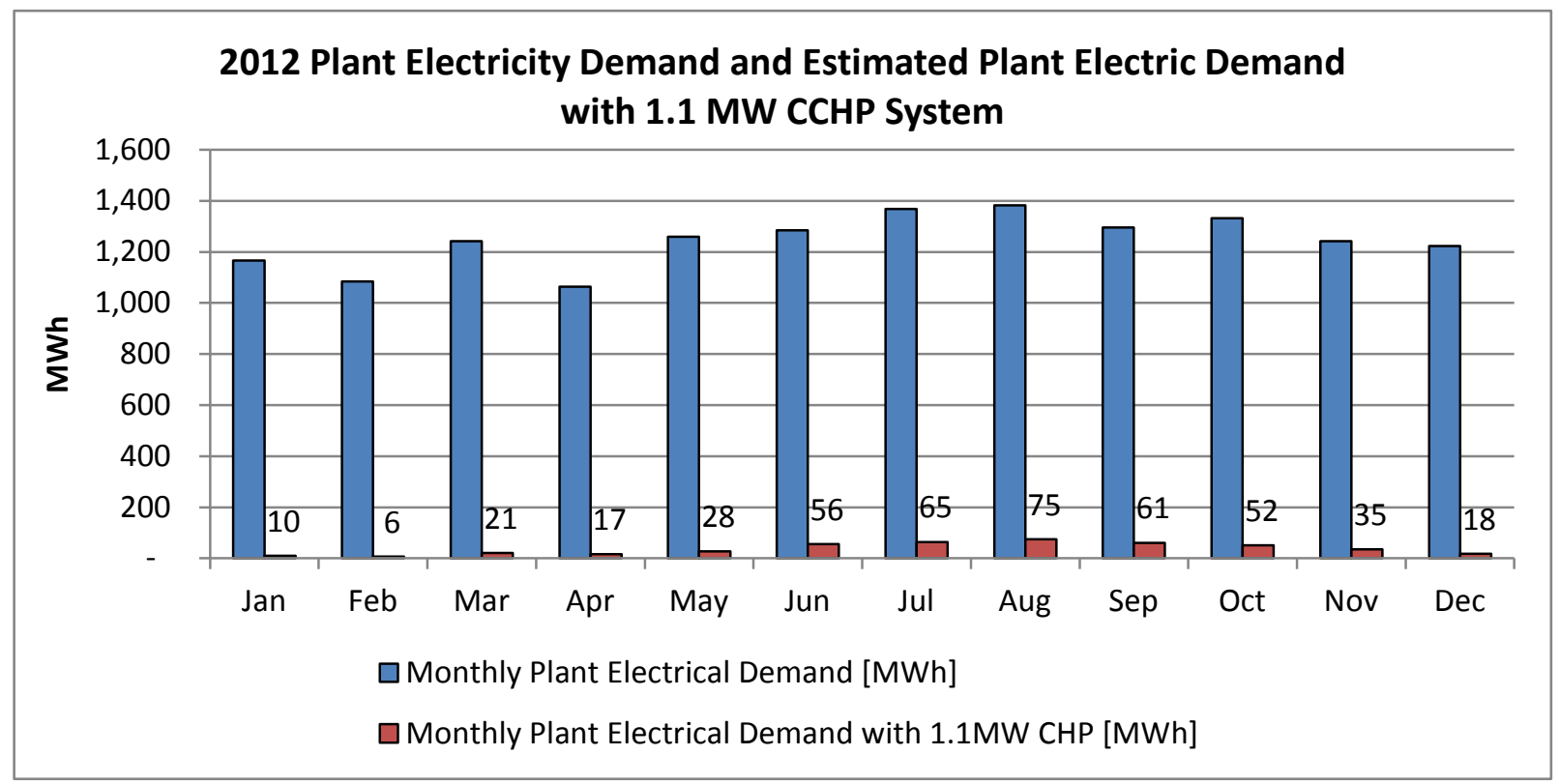

Figure 12. Plant electricity use in 2012 (total 14,943 MWh) and amount to be purchased from the utility with 1.1 MW CCHP system integrated (estimated total $442 \mathrm{MWh}$ ) 


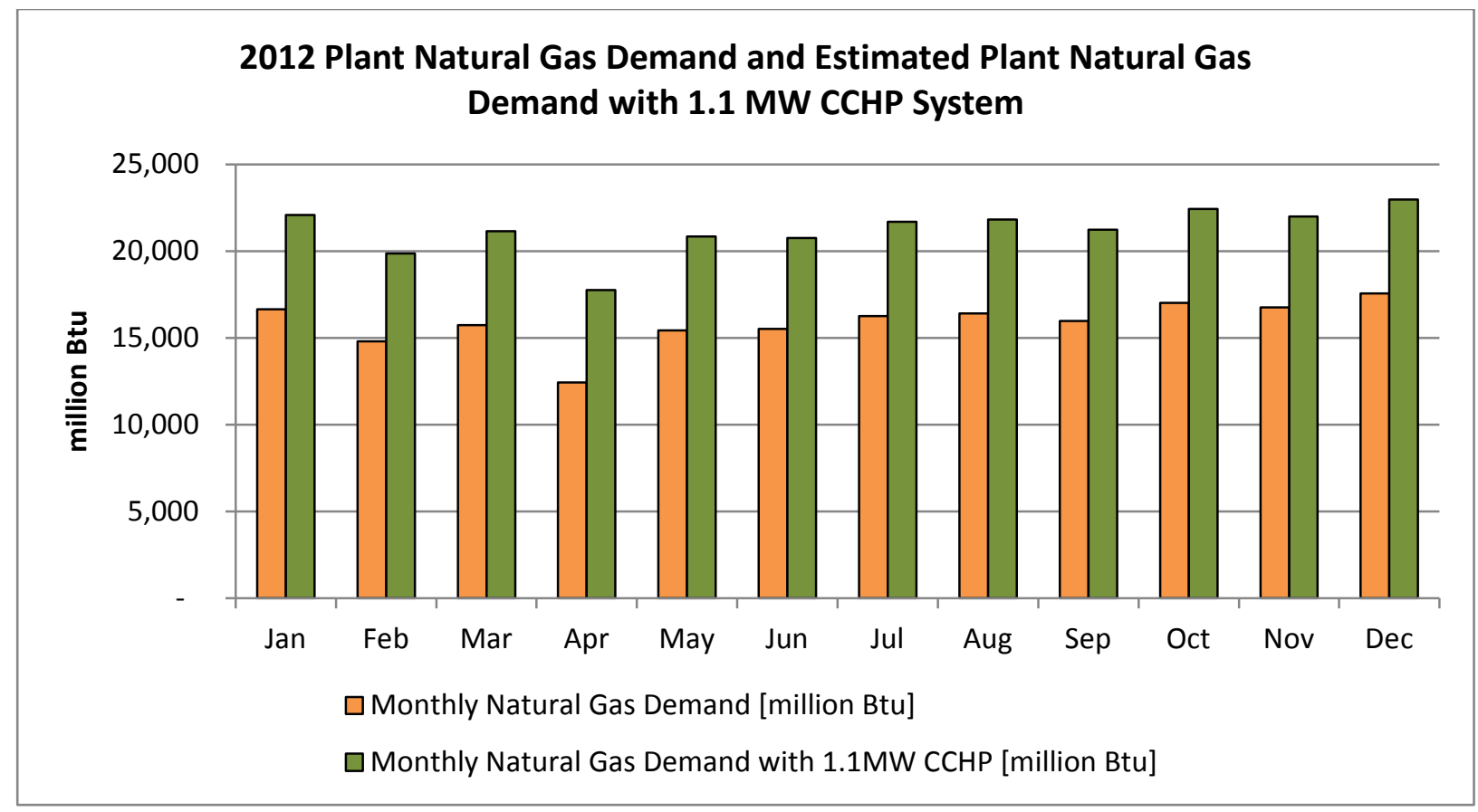

Figure 13. Monthly natural gas demand before and after (estimated) $1.1 \mathrm{MW}$ CCHP integration. Annual total before CCHP was190,569 MMBtu; after, 254,589 MMBtu, an increase of 34\%.

Figure 14 and Figure 15 provide histograms for electricity and natural gas to be purchased from the utility after the integration of a CCHP system. Over the course of a year $53 \%$ of the time no electricity needs to be purchased from utility and $25 \%$ of the time less than $100 \mathrm{~kW}$ is required to be purchased from the utility. With CCHP, the natural gas demand is between 26 and $34 \mathrm{MMBtu} 82 \%$ of the time.

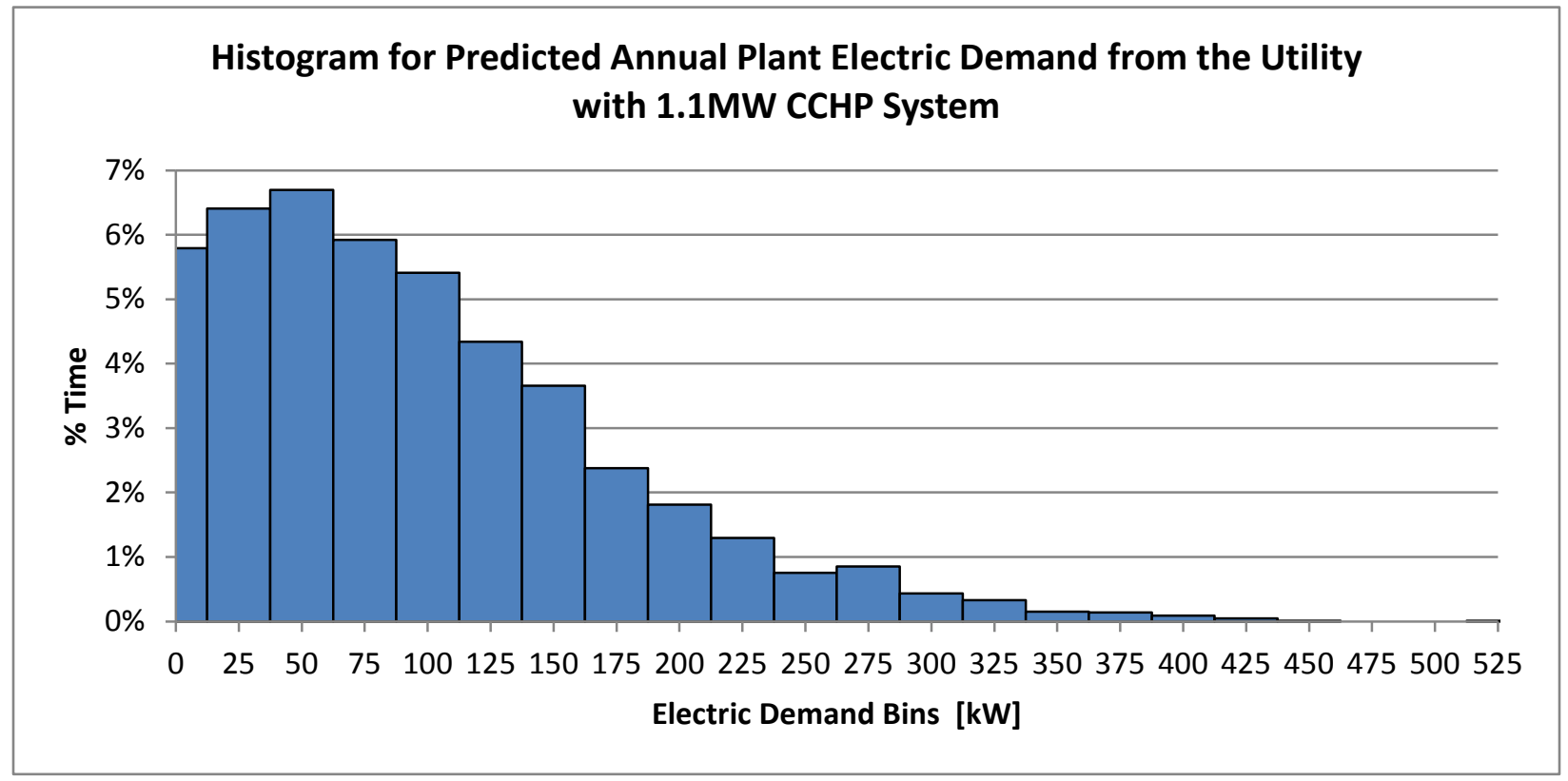

Figure 14. Histogram for estimated annual plant electricity demand from the utility with 1.1 MW CCHP system 


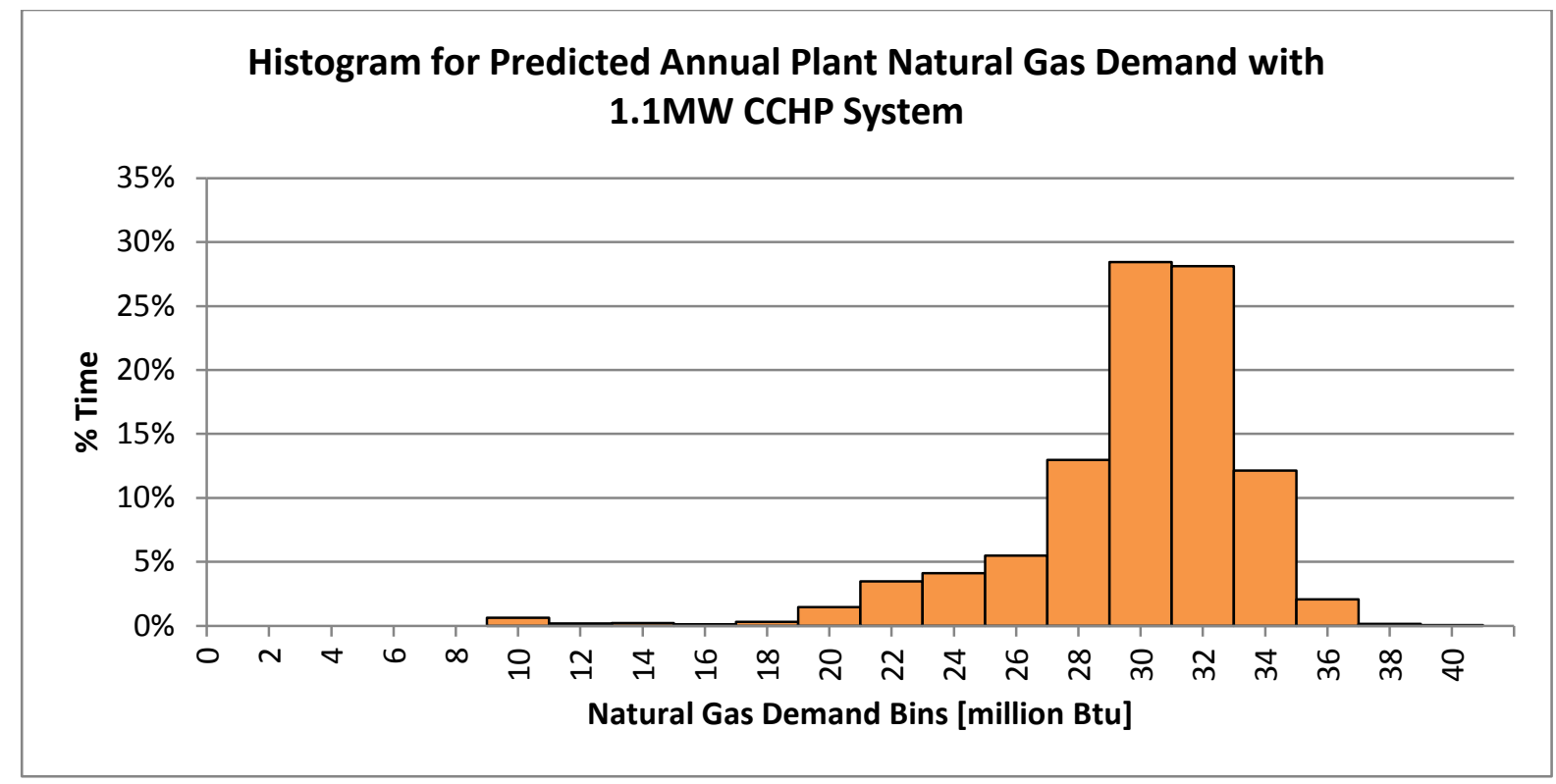

Figure 15. Histogram for estimated annual plant natural gas demand with 1.1 MW CCHP system

Figure 16 and Figure 17 show the utility costs for the plant in 2012 and utility costs estimated after application of a 1.1 MW CCHP system. The reduction of electrical demand is expected to result in a backup charge for the plant, which has not been factored into costs calculated in this study. In addition, it is assumed that the costs for the CCHP system are paid up front with no financing costs. In 2012, the electricity cost was $\$ 1.33$ million and natural gas cost $\$ 857 \mathrm{~K}$. With the $1.1 \mathrm{MW}$ CCHP system, the cost of electricity to be purchased from the utility is estimated to be $\$ 39 \mathrm{~K}$, the cost of natural gas is estimated to be $\$ 765 \mathrm{~K}$, and the cost of CCHP generation (operation, maintenance, and fuel) is estimated to be $\$ 676 \mathrm{~K}$. Total utility cost before CCHP is $\$ 2.19$ million; after CCHP integration it is estimated to be $\$ 1.48$ million. Figure 18 shows total cost of fuel before and after CCHP.

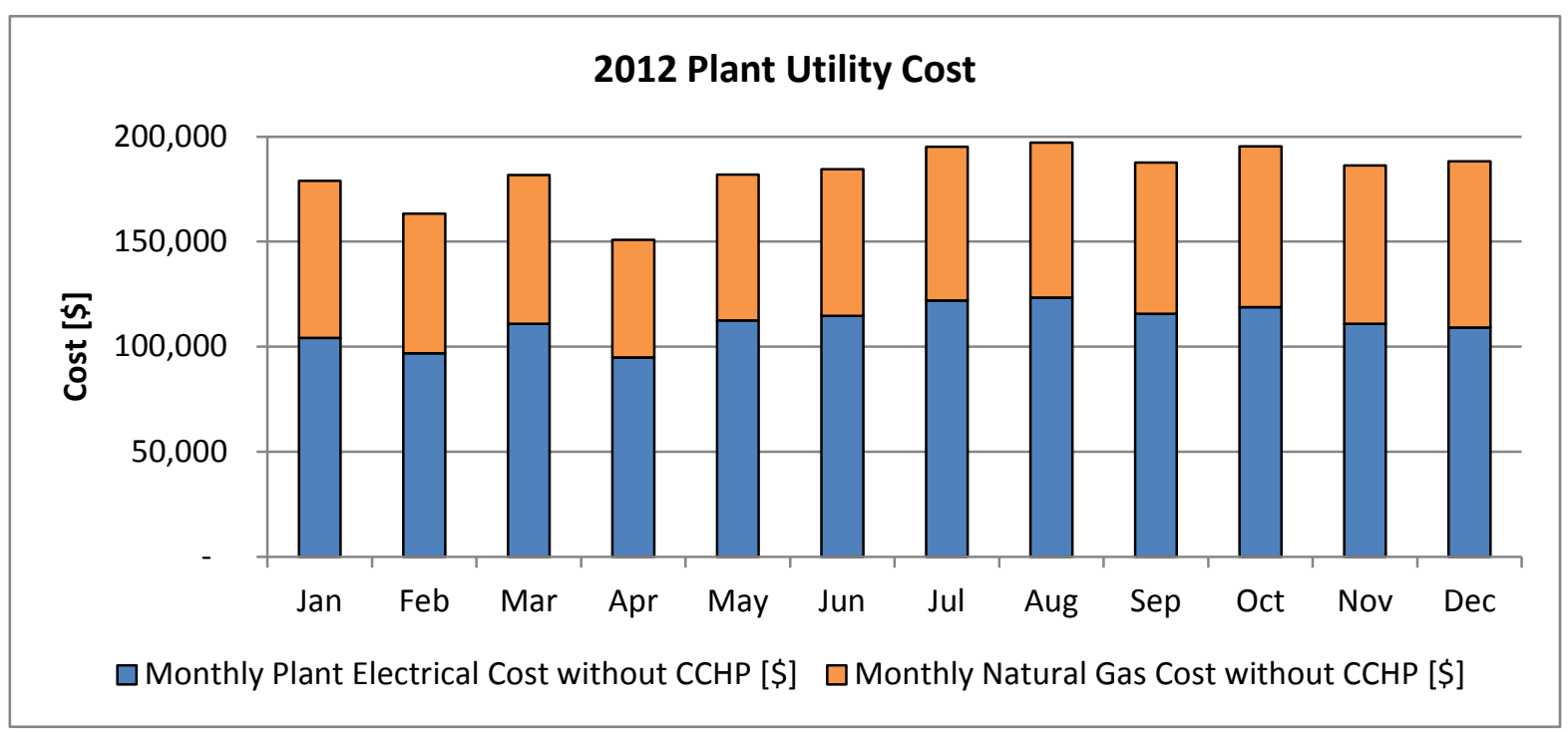

Figure 16. Plant utility cost in 2012. Total cost for electricity $\$ 1.33$ million, total cost for natural gas \$857K. 


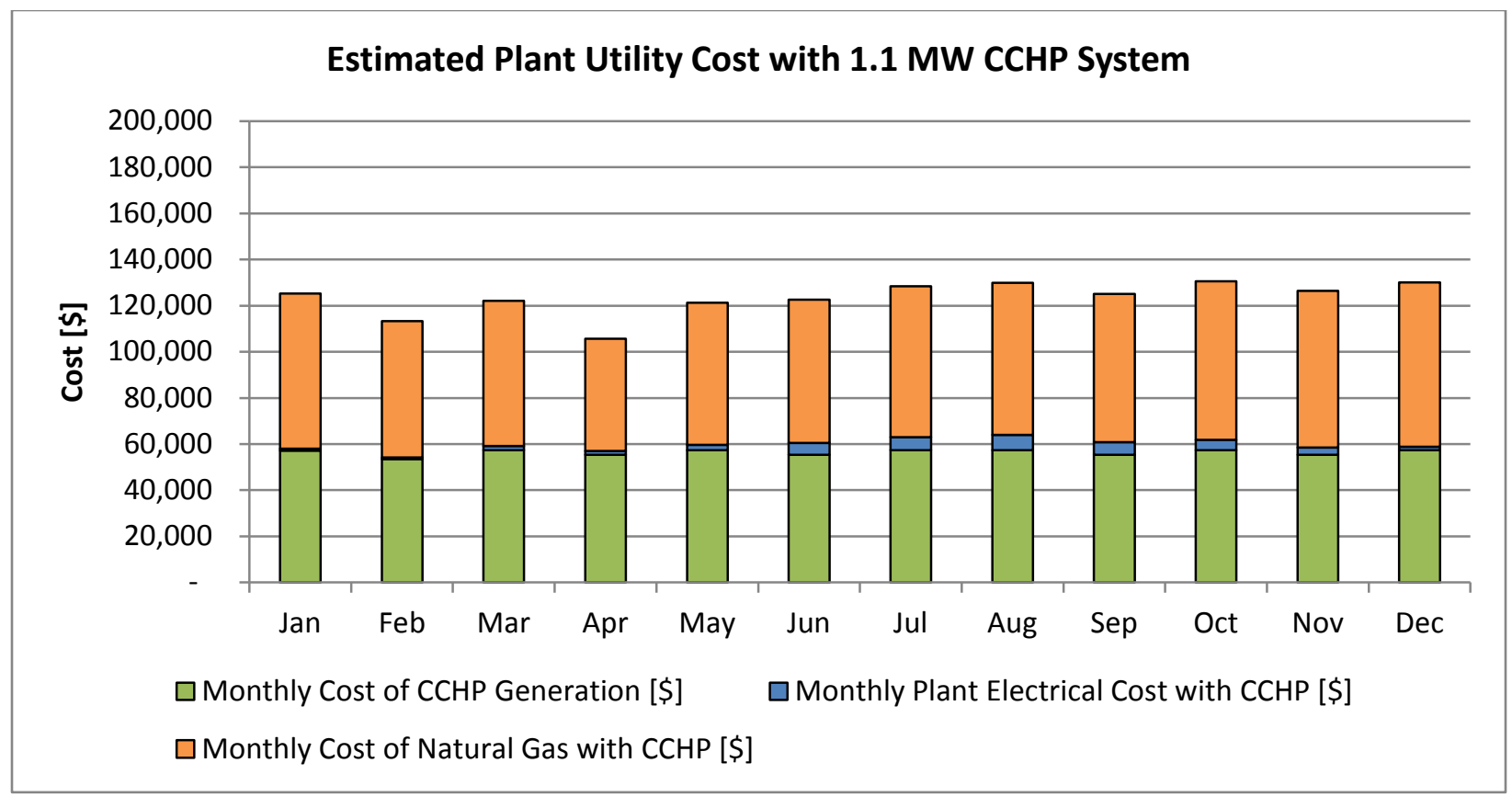

Figure 17. Estimated plant utility cost with 1.1 MW CCHP system integrated. The utility cost includes the cost of fuel to generate electricity and heat using the CCHP.

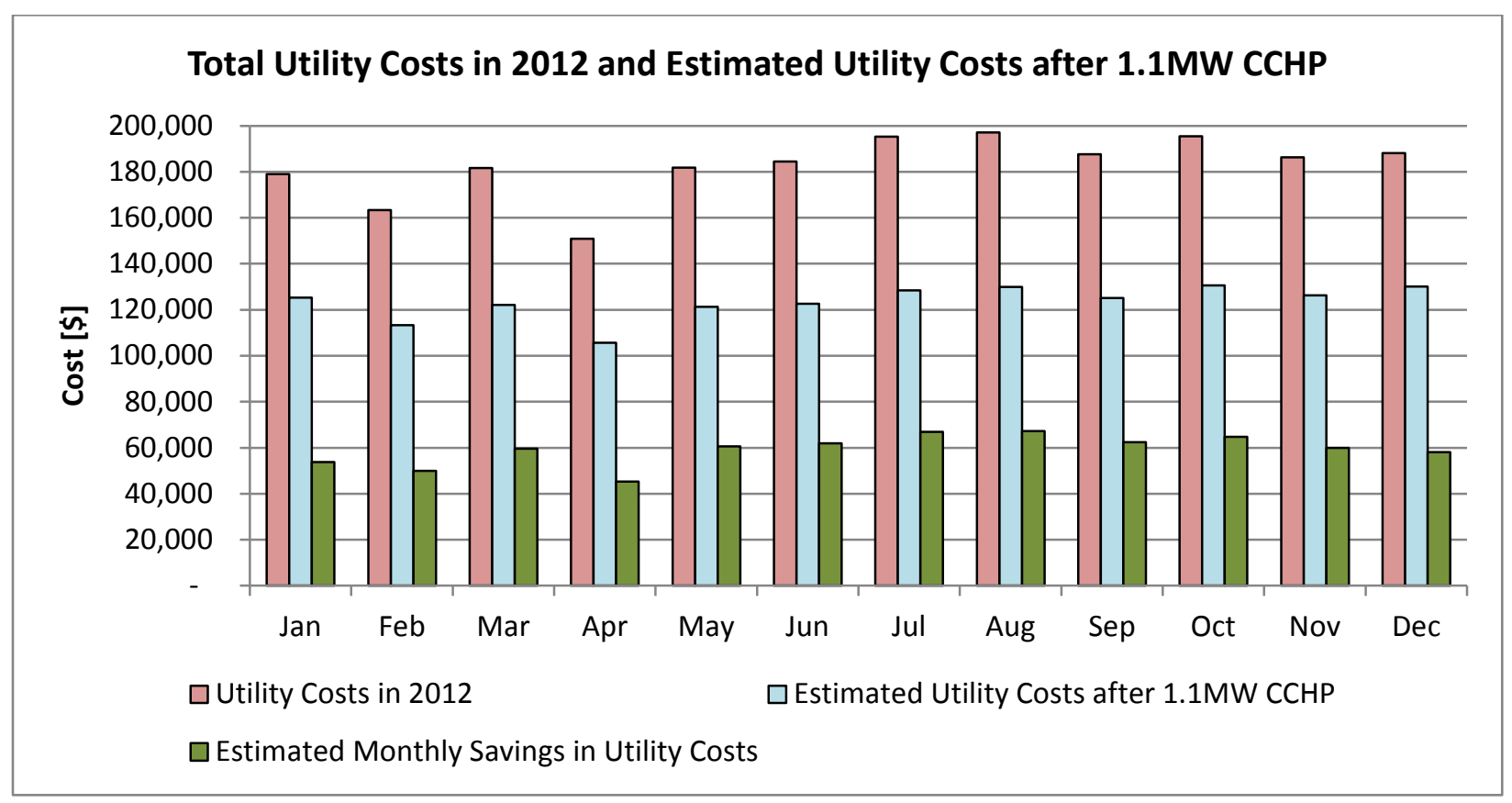

Figure 18. Total utility costs in 2012, estimated utility costs with 1.1 MW CCHP and estimated savings 


\subsection{Power Quality Information}

Power quality (even subcycle) necessitates the installation of ESS. This plant was monitored for power quality and reliability events for 18 months from January 2012 to June 2013. A total of 39 significant power quality and power reliability events were recorded during this time period. Results of the monitoring show events occur randomly during the year and over the course of a day (period of 24 hours). This suggests the need for an active backup power generator and/or ESS that can support the plant during power system failures or power quality issues. However, data shows that the number of events is higher in the months from April to June and also in the month of October. Figure 19 and Figure 20 below show how these events are distributed during one day and the hours of the day that have a higher chance of outages. An estimated cost for the outages, assuming \$15,000 per incident as reported by the plant, is shown in Figure 21.

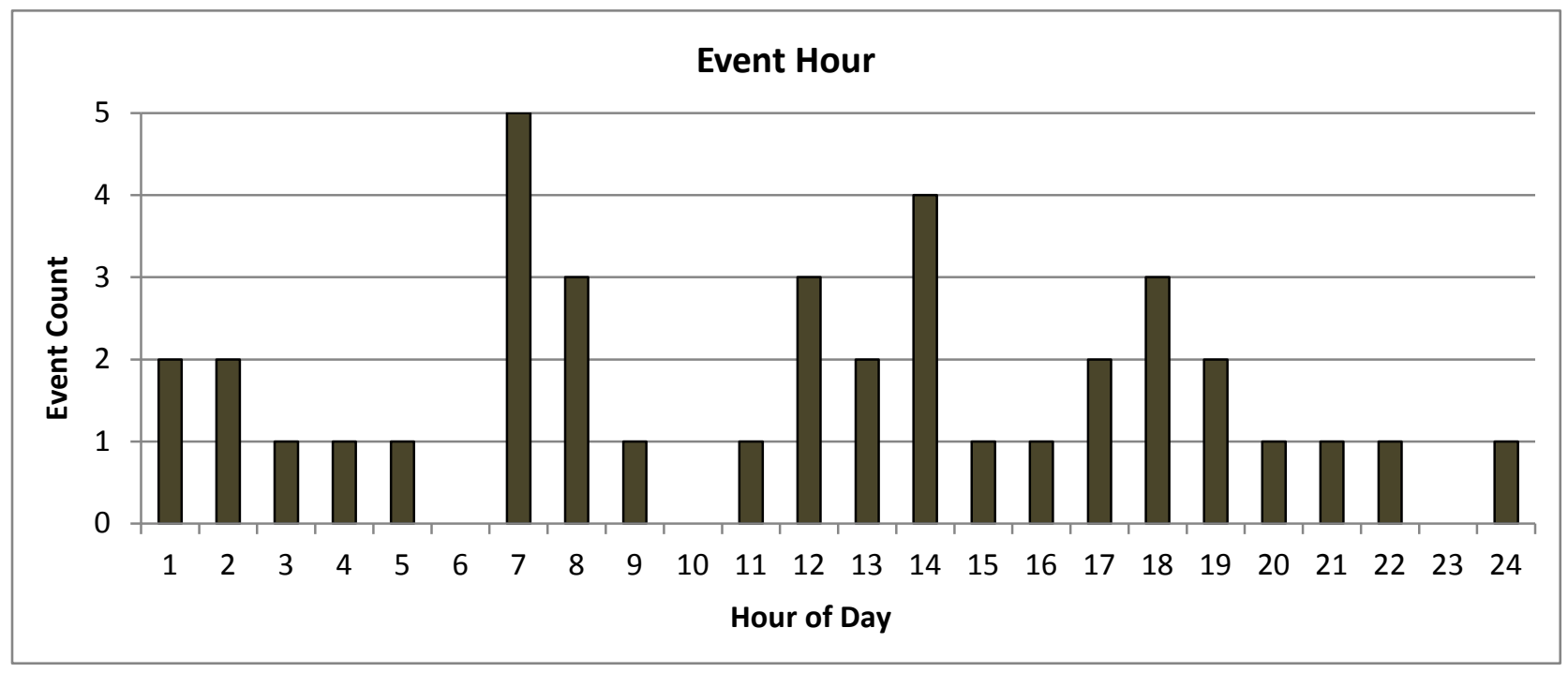

Figure 19. Count of events for each hour of the day

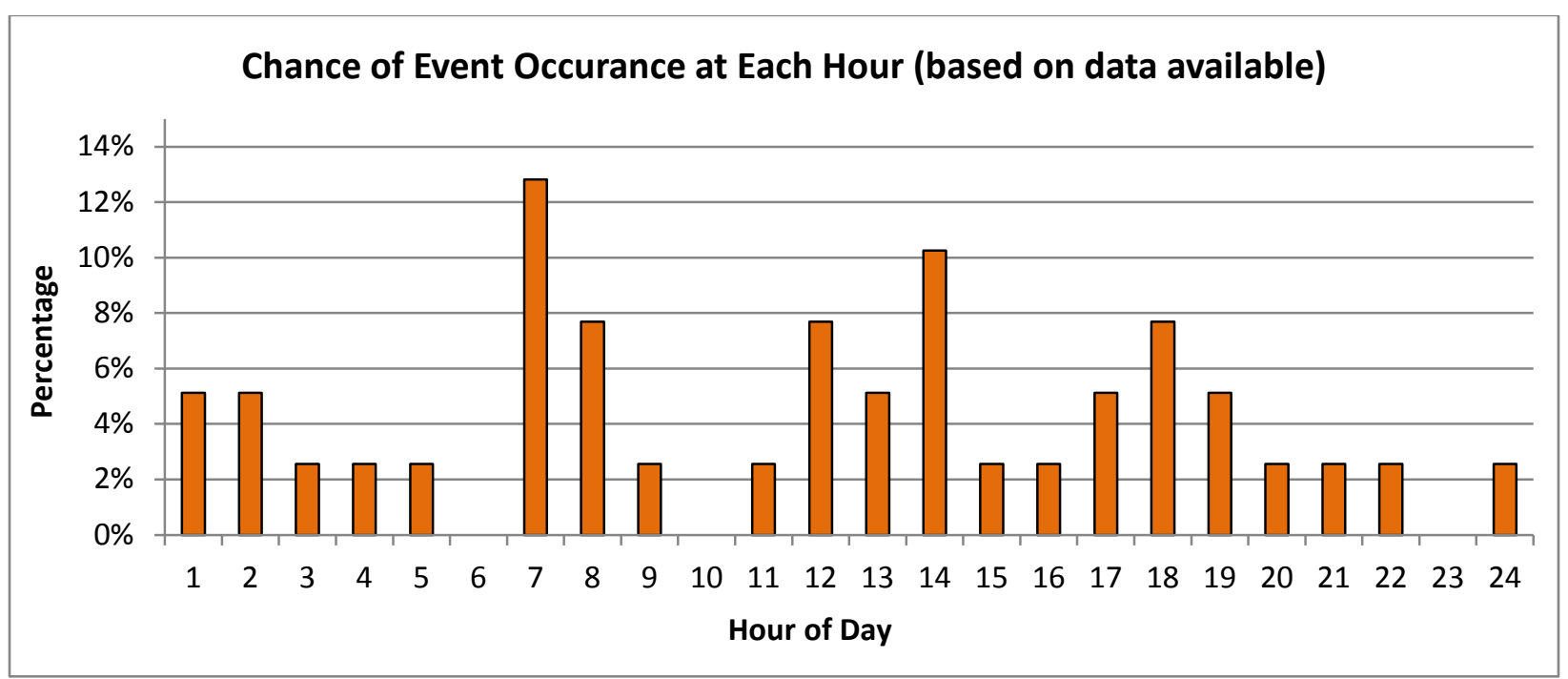

Figure 20. Chance of event occurring during each hour over the course of a day 


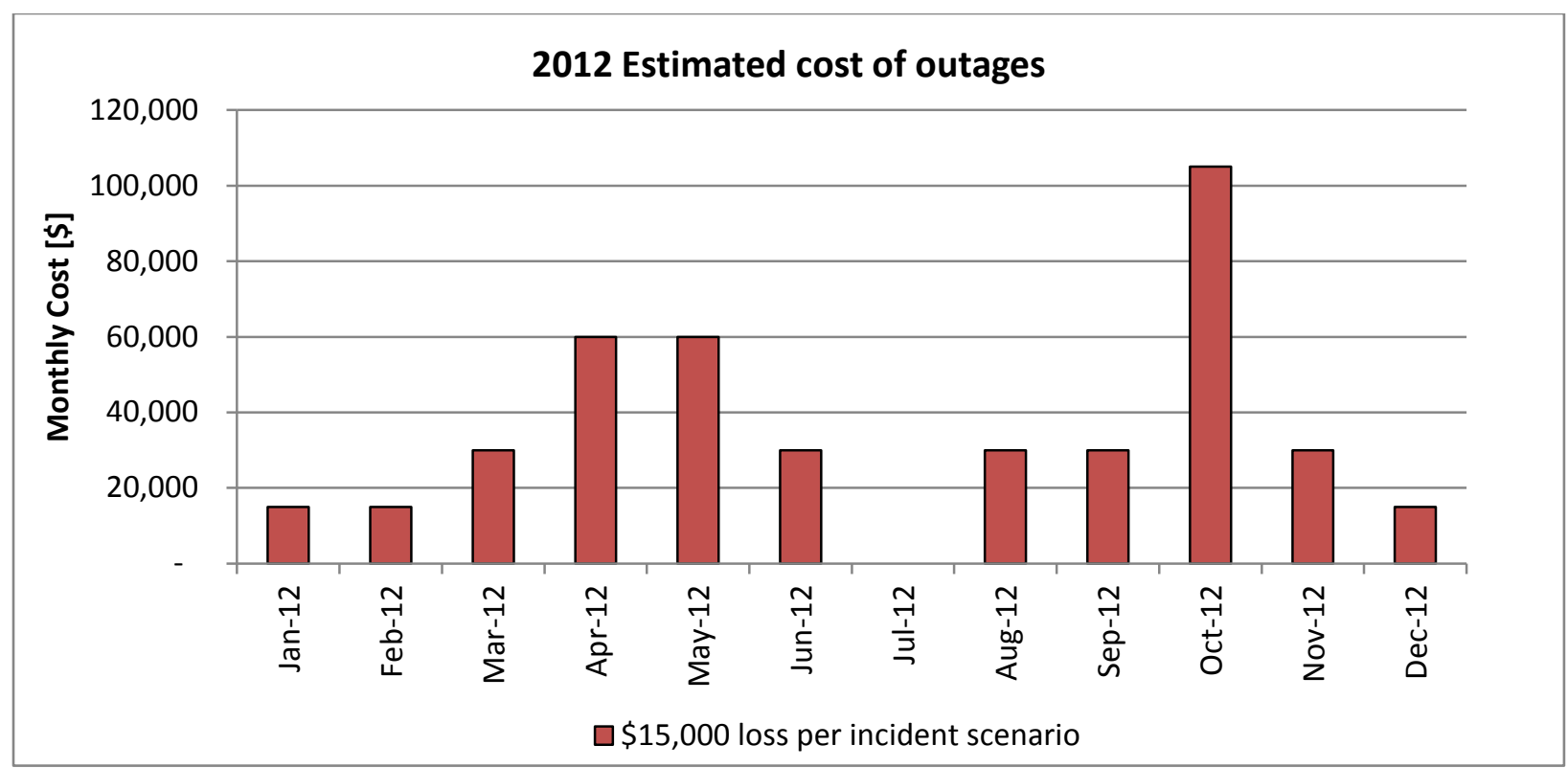

Figure 21. Monthly cost of power incidents estimated based on $\$ 15,000$ per event (total of $\$ 420 \mathrm{~K}$ for 2012)

A discussion of how consideration of integrating ESS can reduce or almost eliminate costs resulting from outages shown in Figure 15 above is presented in Section 6.3. 


\subsection{Current Cost of Energy}

\subsection{Utility}

The plant is located in the Portland area shown in Figure 22. In Figure 23, regional potential for megawatts of production versus cut planes is shown.

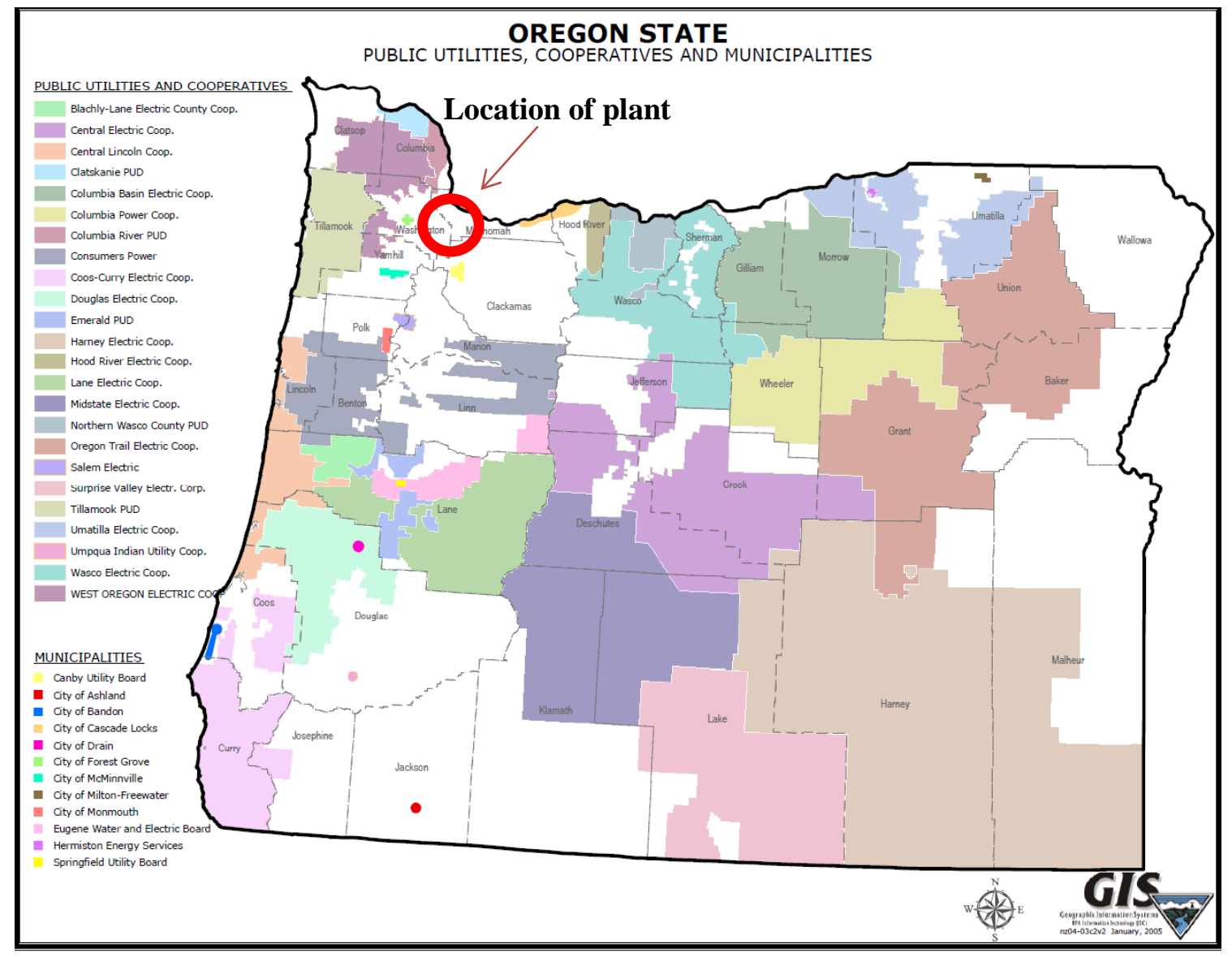

Figure 22. Location of the plant examined in this study 


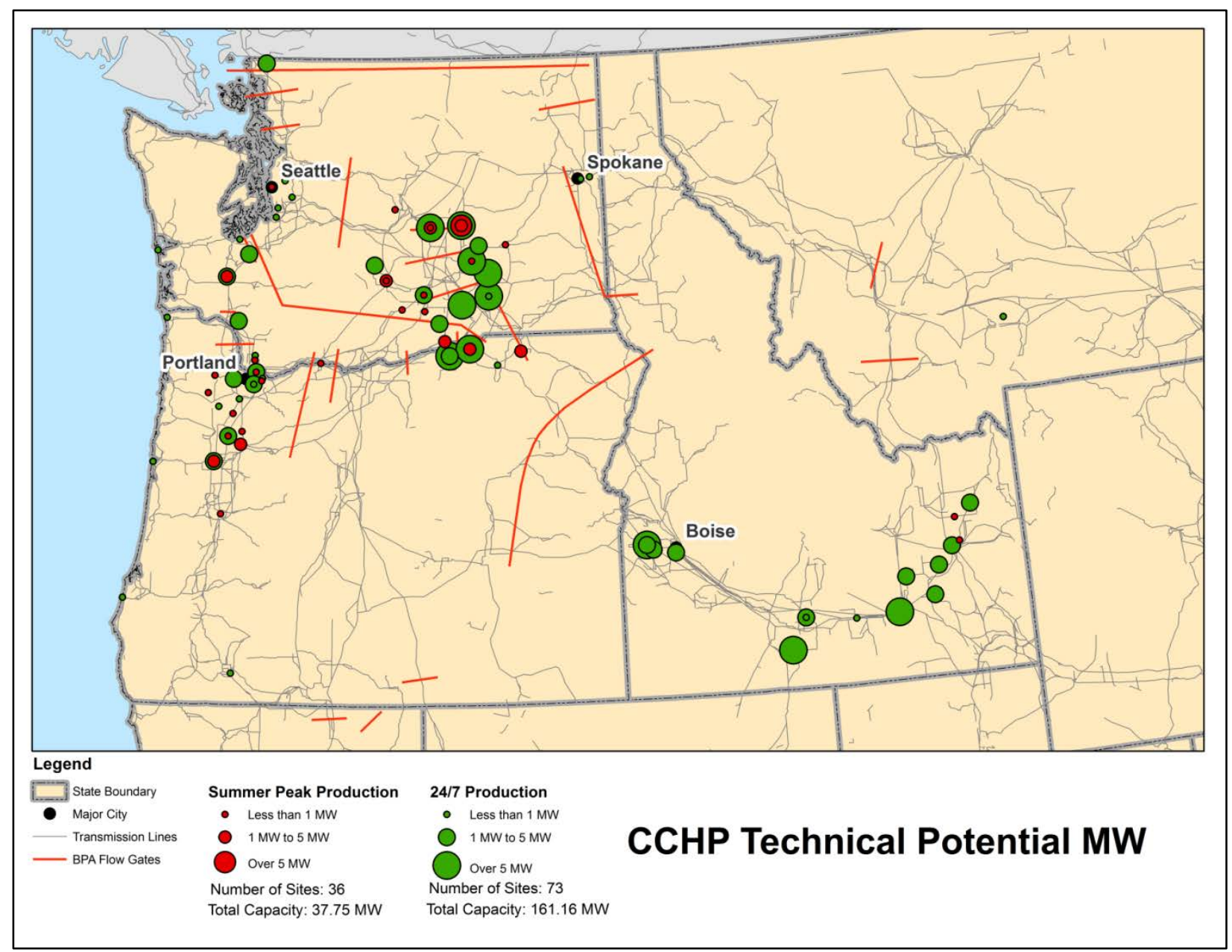

Figure 23. Map showing regional potential for megawatts of production versus cut planes. There are 140 NWFPA members and over 550 food processors in the Pacific Northwest. 


\subsection{Utility Charges and Tariffs}

The local utility serving the plant serves 3026 industrial plants and provides power at an average rate of $\$ 0.07129 / \mathrm{kWh}$. The rate at the plant is $\$ 0.085 / \mathrm{kWh}$. Details of utility charges for Plant $\# 1$ are shown in Table 2.

Table 2. Utility charges at the rate applicable to each large nonresidential customer whose demand has exceeded 1,000 kW at least twice within the preceding 13 months.

\begin{tabular}{|c|c|c|c|}
\hline \multirow[b]{3}{*}{ Basic Charge } & \multicolumn{3}{|c|}{ Delivery Voltage } \\
\hline & $\underline{\text { Secondary }}$ & Primary & Subtransmission \\
\hline & $\$ 1,240.00$ & $\$ 1,000.00$ & $\$ 1,930.00$ \\
\hline \multicolumn{4}{|l|}{ Transmission and Related Services Charge } \\
\hline per kW of monthly On-Peak Demand & $\$ 0.82$ & $\$ 0.79$ & $\$ 0.78$ \\
\hline \multicolumn{4}{|l|}{ Distribution Charges $^{* *}$} \\
\hline \multicolumn{4}{|l|}{$\begin{array}{l}\text { The sum of the following: } \\
\text { per kW of Facility Capacity }\end{array}$} \\
\hline First $4,000 \mathrm{~kW}$ & $\$ 1.64$ & $\$ 1: 60$ & $\$ 1.60$ \\
\hline Over $4,000 \mathrm{~kW}$ & $\$ 0.36$ & $\$ 0.32$ & $\$ 0.32$ \\
\hline per kW of monthly On-Peak Demand & $\$ 1.91$ & $\$ 1.84$ & $\$ 0.85$ \\
\hline \multicolumn{4}{|l|}{ Energy Charge } \\
\hline On-Peak Period ${ }^{\star \star \star}$ & $6.019 \phi$ & $5.837 \phi$ & $5.758 \not$ \\
\hline Off-Peak Period ${ }^{\star \star \star}$ & $5.262 \not$ & $5.080 \not$ & $5.001 \phi$ \\
\hline \multicolumn{4}{|c|}{ See below for Daily Pricing Option description. } \\
\hline \multicolumn{4}{|l|}{ System Usage Charge } \\
\hline Per kWh & $0.327 \phi$ & $0.306 \phi$ & $0.295 \not$ \\
\hline $\begin{array}{l}\text { The Company may require a Customer with dedicate } \\
\text { execute a written agreement specifying a higher min } \\
\text { applicable POD. }\end{array}$ & substation capacity & $\begin{array}{l}\text { and/or redundar } \\
\text { y Capacity and }\end{array}$ & $\begin{array}{l}\text { t distribution facilities to } \\
\text { onthly Demand for the }\end{array}$ \\
\hline $\begin{array}{l}\text { * Peak hours are between 6:00 a.m. and 10:00 p.m. Mo } \\
\text { and 6:00 a.m. Monday through Saturday and all day }\end{array}$ & through Saturc & fff-peak he & between $10: 00 \mathrm{p}$ \\
\hline
\end{tabular}

\subsection{Monthly Cost of Electricity for the Utility to Serve the Plant}

2014 is expected to be a lower than average water year for power generation in the Pacific Northwest due to reduced snowpack. Given the high percentage of hydro power generation in the NW, the cost of electricity for the region is expected to increase. Figure 24 shows Mid-Columbia daily weighted average electricity prices in 2012 (Federal Energy Regulatory Commission) and a prediction of weighted average prices considering a 300\% increase during high peak months (July and August) and a 250\% increase during the rest of the year. Based on the daily mid-Columbia weighted average prices shown in Figure 24, Figure 25 shows the monthly cost of electricity for the utility to serve the plant during 2012 and projects for 2014. 


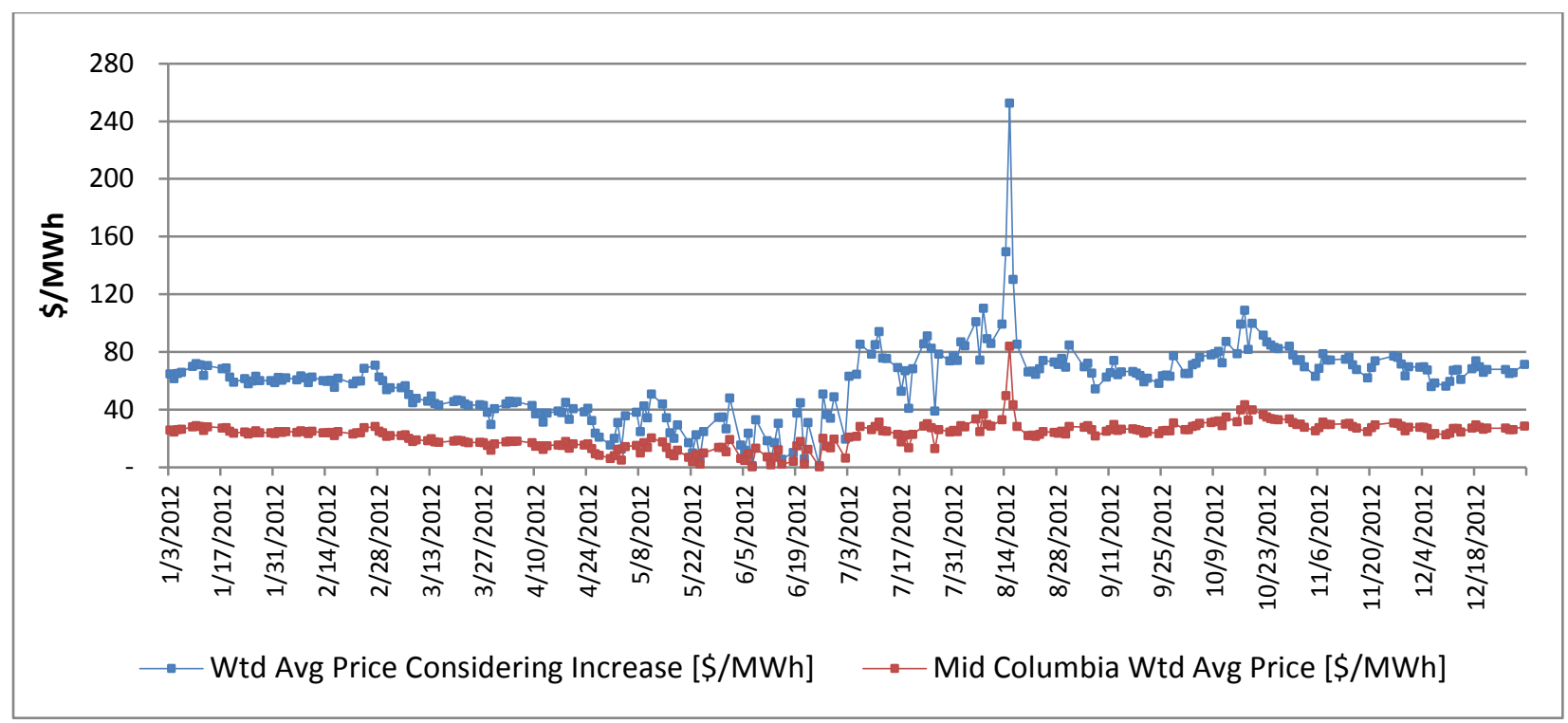

Figure 24. Daily Mid-Columbia weighted average electricity price in 2012 (Federal Energy Regulatory Commission) and a modeled increased price of electricity similar to that experienced during the power crisis of 2000-2001

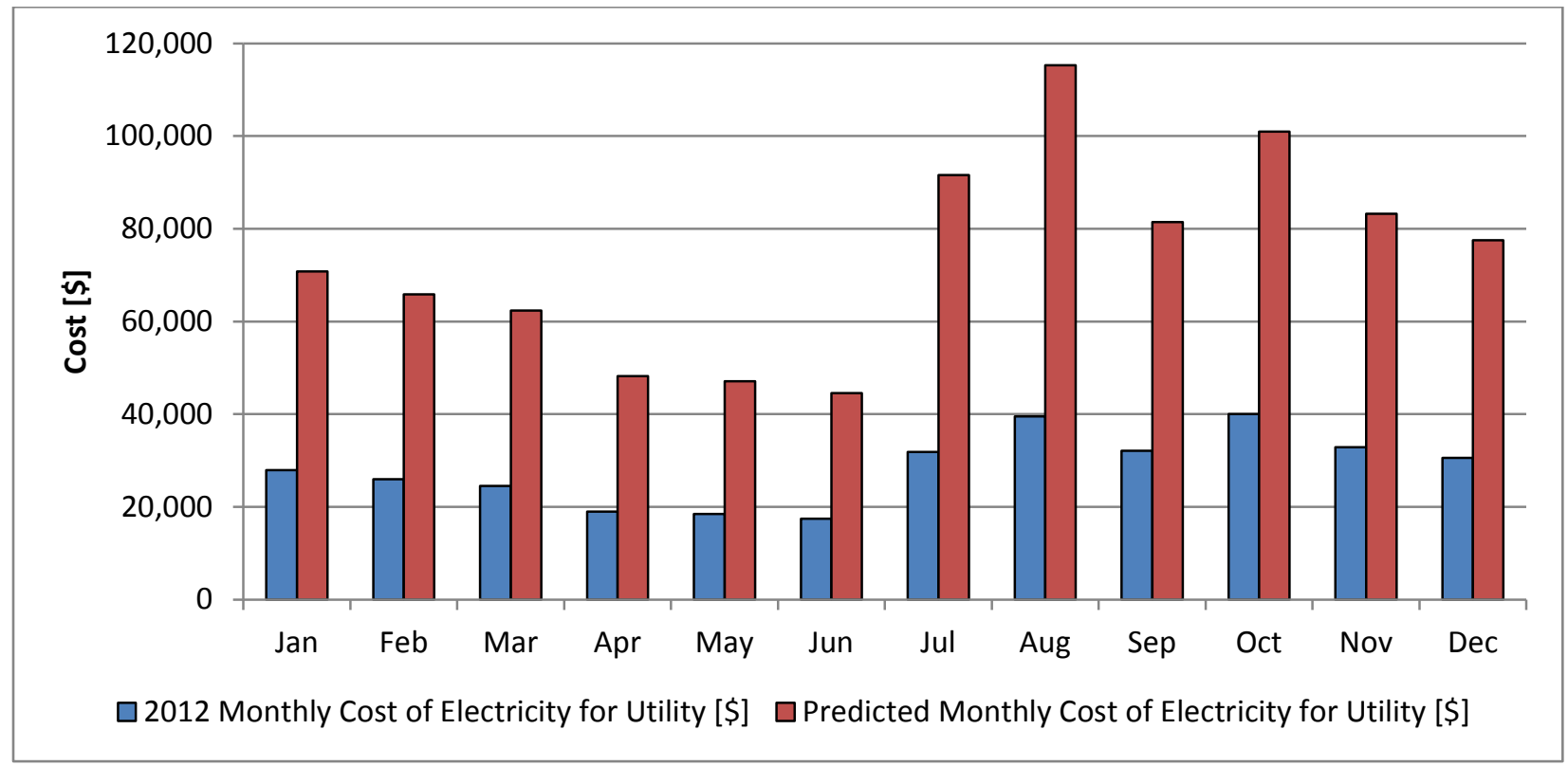

Figure 25. Monthly cost of electricity for the utility to serve Plant \#1 in 2012 (total \$341K per year) and with the modeled price increase to the Mid-Columbia (total $\$ 891 \mathrm{~K}$ per year) 


\subsection{Benefits of Integrated CCHP for the Utility}

The average efficiency of power generation in the United States is $34 \%{ }^{3}$. This means that two-thirds of the energy in the fuel is lost—vented as heat—at most power plants in the United States. In addition to heat losses, about $7 \%{ }^{4}$ of the electricity generated by central plant power stations is lost before it reaches an end user as a result of losses in the transmission and distribution (T\&D) system.

An alternative to this approach is to generate electricity at or near the customer load centers to avoid line losses and use the heat energy resulting from the electricity generation, e.g. implementing CCHP on the utility side of the meter "close" to the plant.

By using waste heat recovery technology to capture a significant proportion of this wasted heat, CHP systems typically achieve total system efficiencies of $65 \%$ to $75 \%{ }^{5}$, compared to only $45 \%{ }^{6}$ for producing electricity and thermal energy separately.

As an example, in data centers where the thermal load is almost entirely cooling rather than heating, CHP can still provide an overall efficiency advantage. The waste heat from the generator is used in absorption chillers to produce cooling, which displaces electricity-powered chillers rather than displacing direct fuel purchases for heating. Therefore, the total electricity provided and displaced by a combined cooling and power system can be up to $135 \%{ }^{6}$ of the on-site generator capacity.

\footnotetext{
${ }^{3}$ Combined Heat and Power, A Clean Energy Solution, pg 3, U.S. Environmental Protection Agency, U.S. Department of Energy, August 2012.

https://www1.eere.energy.gov/manufacturing/distributedenergy/pdfs/chp_clean_energy_solution.pdf

${ }^{4}$ U.S. Energy Information Administration (EIA). Retrieved from http://www.eia.gov/tools/faqs/faq.cfm?id=105\&t=3 on February 28, 2014.

${ }^{5}$ Combined Heat and Power, A Clean Energy Solution, pg 7, U.S. Environmental Protection Agency, U.S. Department of Energy, August 2012. https://www1.eere.energy.gov/manufacturing/distributedenergy/pdfs/chp_clean_energy_solution.pdf

${ }^{6}$ The Role of Distributed Generation and Combined Heat and Power (CHP) Systems in Data Centers, U.S. Environmental Protection Agency, Combined Heat and Power Partnership, August 2007, p. 13. Accessed February 18, 2014 at http://www.epa.gov/chp/documents/datactr_whitepaper.pdf
} 


\subsection{Historic and Current Cost of Energy Purchased by Plant \#1}

In this section, the historic cost of electricity for the plant is detailed in Table 3, Figure 26 and Figure 27 show the monthly costs of electricity and natural gas for the plant in 2012 .

Table 3. Historic breakdown of electricity cost (Source: Data collected from the plant)

\begin{tabular}{|c|c|c|c|c|}
\hline Analysis Columns & Statistics & 2011 & 2012 & 2013 \\
\hline Basic Charge & Sum & $\$ 23,998.15$ & $\$ 24,600.00$ & $\$ 32,642.00$ \\
\hline System Usage Charge & Sum & $\$ 43,436.77$ & $\$ 43,553.28$ & $\$ 53,737.63$ \\
\hline Energy Usage Charge & Sum & $\$ 30,450.79$ & $\$ 31,123.02$ & $\$ 38,355.63$ \\
\hline Demand Usage Charge & Sum & $\$ 1,477.83$ & $\$ 1,173.92$ & $\$ 1,022.56$ \\
\hline Reactive Demand Usage Charge & Sum & $\$ 1,672.00$ & $\$ 1,871.00$ & $\$ 1,876.00$ \\
\hline Transmission Charge & Sum & $\$ 26,204.71$ & $\$ 27,824.34$ & $\$ 28,076.96$ \\
\hline Distribution Charge & Sum & $\$ 75,759.76$ & $\$ 78,818.77$ & $\$ 78,263.17$ \\
\hline Reactive Demand Billed & Sum & $\$ 3,344.00$ & $\$ 3,742.00$ & $\$ 3,752.00$ \\
\hline On-Peak Usage Charges & Sum & $\$ 489,475.69$ & $\$ 524,539.49$ & $\$ 544,995.36$ \\
\hline Off-Peak Usage Charges & Sum & $\$ 314,965.25$ & $\$ 343,282.63$ & $\$ 352,051.75$ \\
\hline On-Peak Demand Charges & Sum & $\$ 55,780.52$ & $\$ 61,666.25$ & $\$ 62,574.99$ \\
\hline Off-Peak Demand Charges & Sum & - & - & - \\
\hline Facility Charges & Sum & $\$ 114,987.18$ & $\$ 78,818.77$ & $\$ 78,263.17$ \\
\hline Renewable Charges & Sum & - & - & - \\
\hline Light Charge & Sum & $\$ 2,509.04$ & $\$ 2,508.84$ & $\$ 2,508.84$ \\
\hline Light Adjustments & Sum & $\$ 30.72$ & $\$ 65.36$ & $\$ 52.15$ \\
\hline Total & & $\$ 1,184,092$ & $\$ 1,223,588$ & $\$ 1,278,172$ \\
\hline $\begin{array}{l}\text { Percent of bill based on per-kW } \\
\text { charges }\end{array}$ & & $14 \%$ & $11 \%$ & $11 \%$ \\
\hline
\end{tabular}




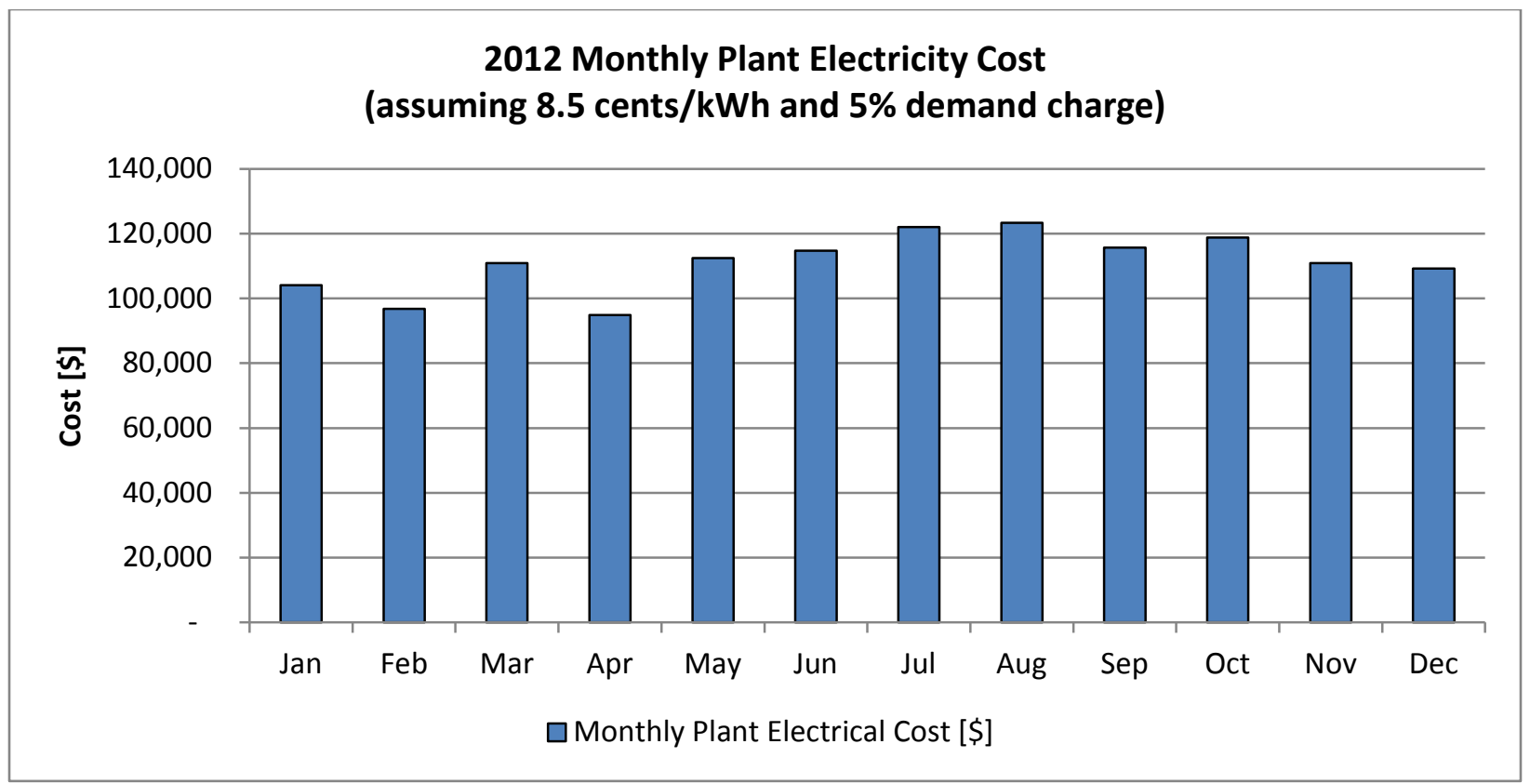

Figure 28. Plant monthly cost of electricity; total \$1.3 million for 2012

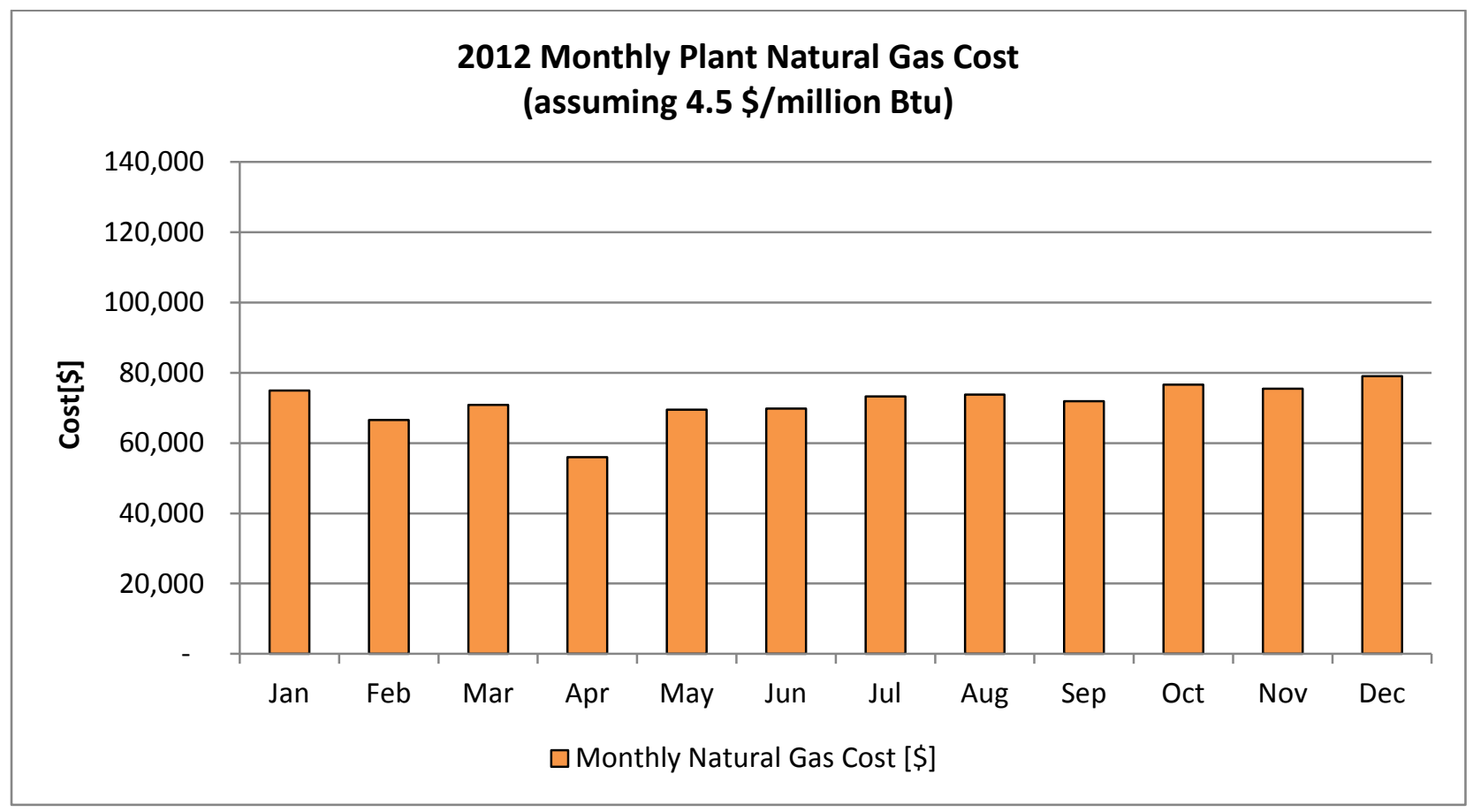

Figure 29. Plant monthly cost of natural gas; total \$857K for 2012 


\subsection{Modeling Approach}

To enable an accurate estimation, a modeling framework was defined to effectively select and size a CCHP system that maximizes the economic and environmental benefits of integrating CCHP into food processing plants. Models were constructed in spreadsheet to maximize the flexibility needed for detailed data-driven modeling and analysis of behavior of less known/emerging systems such as CCHP. This provided a basis to create a system-specific modeling and simulation engine for commercialization.

The modeling approach enabled us to effectively use actual measured time-series energy use data available from the plant and successfully analyze data needed for system selection, sizing, and calculations of energy, savings, and emissions. The flexibility afforded by the spreadsheet modeling provided the ability to estimate the benefits of integrating a CCHP system with potential future electric rate increases. The framework of the modeling approach used is illustrated in Figure 30 and Figure 31.

The steps involved in this modeling can be listed as follows:

1. The measured data for fuel (gas and electricity) used in the plant was processed.

2. The peak, base, and average heating and cooling demands of the plant were calculated to find and match CCHP energy output with the plant demand.

3. Based on the ratio of electricity demand to heat demand as well as the operation and maintenance cost, the type of prime mover was selected: internal combustion engine/microturbine or fuel cell.

4. An absorption heat pump (AHP) was selected such that it provides the capacity and chilled water temperature needed.

5. Energy use, cost and emissions were calculated.

Installation criteria for integrating the CCHP supply with the plant system configuration were considered, including integration of the AHP with an ammonia refrigeration system. The physical location for installing the system was considered such that it would be near both steam and refrigerant lines to connect the new refrigerant source from the AHP. 


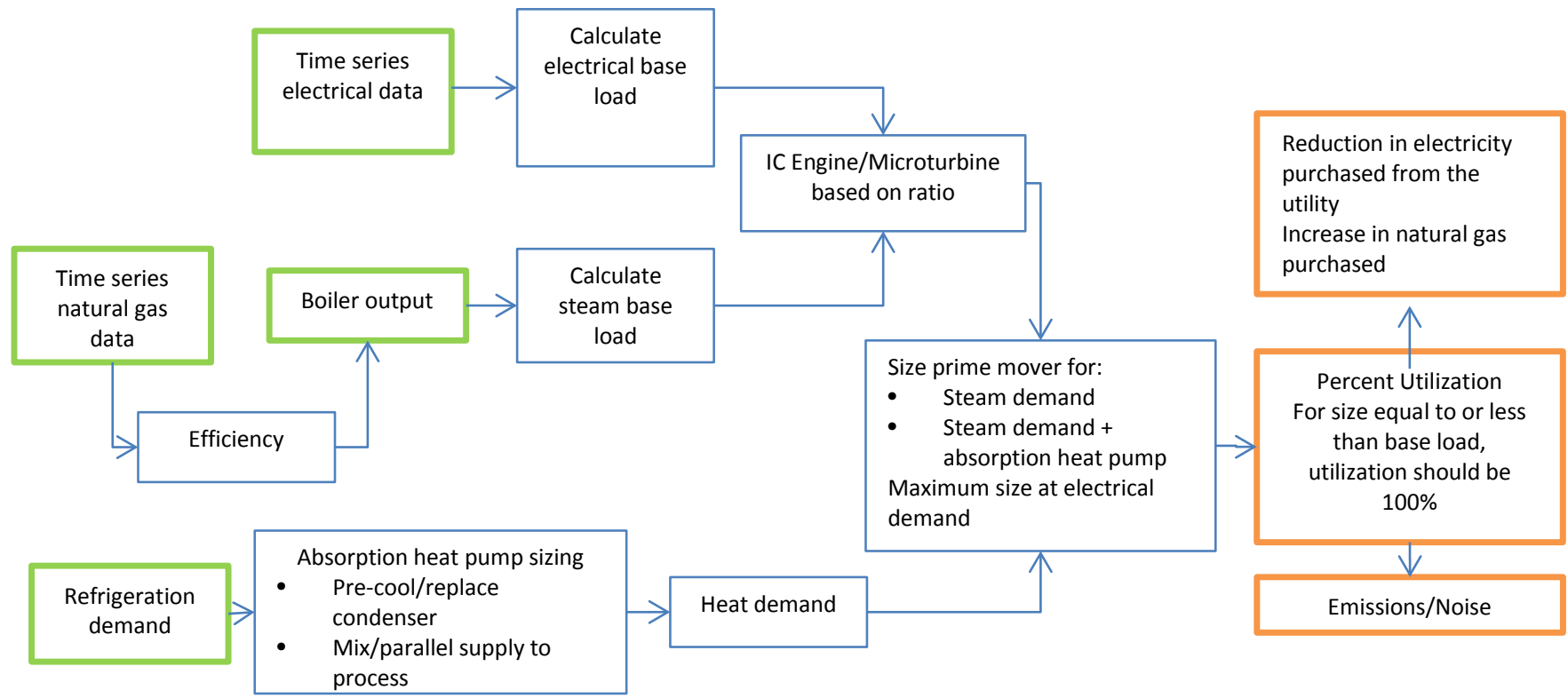

Figure 30. The overall process for sizing a CCHP system

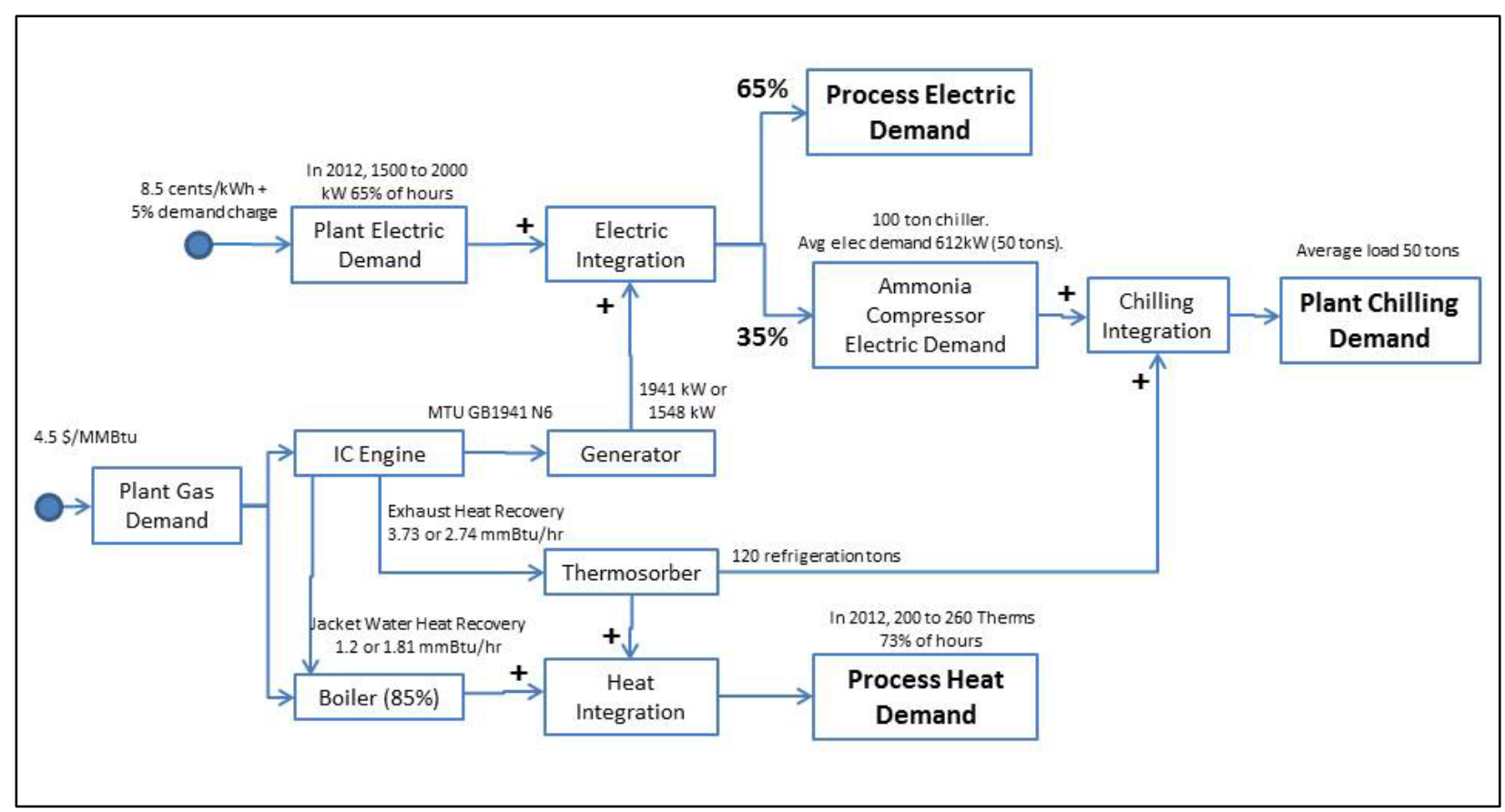

Figure 31. A high-level diagram of the calculation process to determine the electric and heat utilization factors for the CCHP systems 


\subsection{CCHP Equipment Selection and Sizing}

\subsection{Prime Mover Systems Considered}

The prime mover in CCHP uses natural gas to produce electricity on site, and the exhaust heat from the engine as well as cooling jacket water heat is recovered to generate steam, hot water, and refrigeration for use at the plant. Prime movers based on internal combustion engines are considered as documented in Table 4. In this study, specifications for internal combustion engines from the $\mathrm{MTU}^{\mathrm{TM}, 7}$ brand are considered. However, specifications from other brands such as Caterpillar ${ }^{\mathrm{TM}}$ and Cummins ${ }^{\mathrm{TM}}$ may also be considered in the future. The initial cost and maintenance complexity of fuel cells and microturbines compared to prime movers based on internal combustion engines reduced their feasibility for consideration in this application.

Table 4. Key characteristics of prime movers considered

\begin{tabular}{|c|c|c|c|c|c|c|c|}
\hline $\begin{array}{c}\text { Manufacturer } \\
\text { and Model No. }\end{array}$ & $\begin{array}{c}\text { Cost of } \\
\text { Delivered } \\
\text { System } \\
{[\$]}\end{array}$ & $\begin{array}{c}\text { Electrical } \\
\text { Power } \\
{[\mathrm{kW}]}\end{array}$ & $\begin{array}{c}\text { Thermal } \\
\text { Output } \\
{[\mathrm{kW}]}\end{array}$ & $\begin{array}{c}\text { Thermal } \\
\text { Output } \\
\text { Exhaust } \\
\text { [MMBtu/hr] }\end{array}$ & $\begin{array}{c}\text { Thermal } \\
\text { Output Jacket } \\
\text { Water } \\
\text { [MMBtu/hr] }\end{array}$ & $\begin{array}{l}10 \text { Year } \\
\text { Avg. } \\
\text { Cost } \\
{[\$ / k W h]}\end{array}$ & $\begin{array}{c}\text { Energy } \\
\text { Input } \\
{[\mathrm{kW}]}\end{array}$ \\
\hline $\begin{array}{l}\text { MTU } \\
\text { GB 1941 N6 }\end{array}$ & $\$ 2.26 \mathrm{M}$ & 1,941 & 1,444 & 3.73 & 1.20 & 0.068 & 4,685 \\
\hline $\begin{array}{l}\text { MTU } \\
\text { GB } 1548 \text { N6 }\end{array}$ & $\$ 2.22 \mathrm{M}$ & 1,548 & 1,333 & 2.74 & 1.81 & 0.067 & 3,765 \\
\hline $\begin{array}{l}\text { MTU } \\
\text { GB } 1149 \text { N6 }\end{array}$ & $\$ 1.85 \mathrm{M}$ & 1,149 & 586 & 0.89 & 1.11 & 0.067 & 2,822 \\
\hline
\end{tabular}

\footnotetext{
${ }^{7}$ MTU Onsite Energy is a brand of Rolls-Royce Power Systems AG. http://www.mtuonsiteenergy.com/home
} 


\subsection{Absorption Heat Pump Technology}

Absorption heat pumps are thermally powered engines used to provide both heating and cooling. These systems can simultaneously deliver hot water $\left(150^{\circ} \mathrm{F}\right)$ and chilled fluid (20 to $\left.45^{\circ} \mathrm{F}\right)$. Lower temperature refrigeration can also be delivered that provides for a temperature as low as minus $40^{\circ} \mathrm{F}$ when combined with a cooling tower or air cooling. The heat source can be steam, exhaust (e.g., from an engine, boiler, or turbine), solar hot water, geothermal hot water, or engine jacket water; the water temperature must be higher than $250^{\circ} \mathrm{F}$ for heat-pumped hot water and $180^{\circ} \mathrm{F}$ for refrigeration. Heat sources with higher temperatures are required to provide refrigeration below minus $40^{\circ} \mathrm{F}$. Table 5 shows a summary of different types of AHPs.

For each Btu/hr of heat supplied, an AHP can deliver 1.6 Btu/hr of hot water and 0.6 Btu/hr of refrigeration capacity, with a net COP of 2.2.

Table 5. Summary of AHP systems from 3 case studies (Source: Energy Concepts)

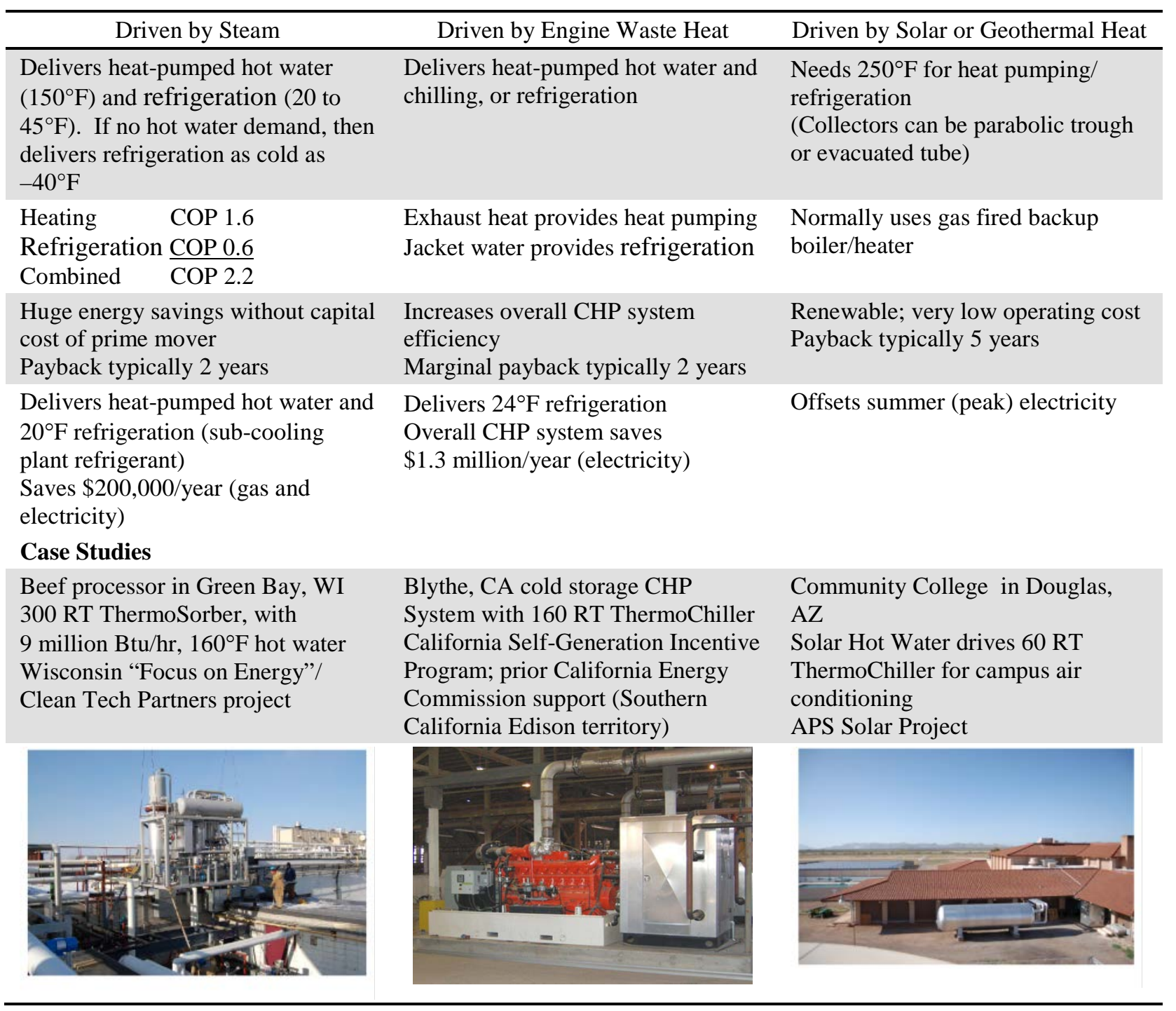




\subsection{Energy Storage System}

Integration of an energy storage system (ESS) should be considered to ensure that power quality is appropriately addressed. Without an efficient and reliable ESS, the CHP generator needs to be oversized to ensure the reliability of the system and to enable the load to be met at all times, especially during periods of high demand. However, because CHP systems run continuously throughout the day, they result in excess electricity being generated during hours when demand is low. Excess generation then is either wasted or necessitates consideration of putting it back into the grid. This results in lower efficiency of the system than necessary. By adding energy storage, energy can be stored during hours of low demand and be supplied when demand is high. This eliminates the need to purchase electricity from the grid during hours of high demand or as noted above having to address grid interconnection issues. By adding energy storage, the following goals can be achieved:

1. The CHP generator can be downsized, which results in:

a. reduction in the cost of fuel for CHP

b. decrease in the capital cost of CHP system

c. reduction in emissions

2. The number of power outages is reduced by providing a more reliable power supply.

3. The system provides reliable "just-in-time” energy delivery.

4. Operating efficiency is improved.

5. Insurance costs associated with product losses are reduced.

A system such as S\&C Electric Company’s PureWave Uninterruptible Power Supply (UPS) System (Figure 32) offers an alternative solution to distributed low-power uninterruptible power supplies. A PureWave system of size $250 \mathrm{~kW}$ costs about $\$ 160,000$ plus installation cost. This system is capable of delivering recovery power in 2 to 4 milliseconds. The PureWave UPS system offers a high efficiency of 98.5\%. A PureWave UPS system can be installed outdoors, which eliminates additional costs and safety considerations associated with interior ESS applications.

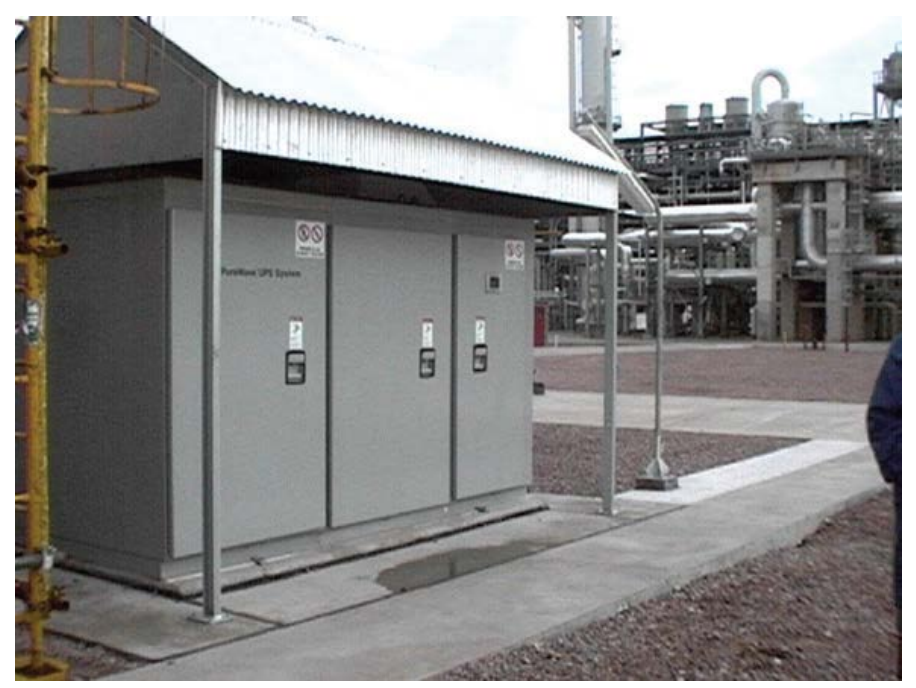

Figure 32. PureWave UPS system installed at a continuous process manufacturing plant 
The maximum power that needs to be purchased from the utility with the CCHP system integrated is about $500 \mathrm{~kW}$; it is assumed that one $250 \mathrm{~kW}$ UPS system will support the critical loads. Such UPS systems provide the advantage of being able to add additional storage capacity with minimal installation costs.

\subsection{CCHP Equipment Selection and Sizing}

A summary of assumptions and results for energy and costs from sizing calculations are shown in Table 6, Table 7, Table 8, Table 9, and Table 10.

Table 6. Assumptions used in electrical calculations for CCHP integration

\begin{tabular}{lc}
\hline Electricity cost for plant [\$/kWh] & 0.085 \\
Demand charge [\%] & $5 \%$ \\
Electricity demand for plant cooling system that will be offset by AHP & $5,229,976$ \\
(35\%) [kWh/yr] & \\
Electricity demand by plant process [kWh/yr] & $9,712,812$ \\
Annual plant electrical demand [kWh/yr] & $\mathbf{1 4 , 9 4 2 , 7 8 8}$ \\
Cost of electricity purchased from utility in $\mathbf{2 0 1 2}[\mathbf{\$} / \mathbf{y r}]$ & $\mathbf{\$ 1 , 3 3 3 , 6 4 4}$ \\
Cost of electricity for the utility to serve the plant [\$/yr] & $\$ 341,238$ \\
\hline
\end{tabular}

Table 7. Results for 2012 for electrical demand from CCHP integration calculations

\begin{tabular}{lccc}
\hline & MTU & MTU & MTU \\
\cline { 2 - 4 } & GB 1941 N6 & GB 1548 N6 & GB 1149 N6 \\
\hline CCHP electrical output to be used in calculation [kW] & 1,941 & 1,548 & 1,149 \\
CCHP total electrical output (assuming 24×7×366) [kWh/yr] & $17,049,744$ & $13,597,632$ & $10,092,816$ \\
Electrical output not used [kWh/yr] & $7,334,991$ & $3,883,715$ & 821,339 \\
\% electrical output not used & $43 \%$ & $29 \%$ & $8 \%$ \\
Number of hours during which electrical output is fully used & 1 & 16 & 4,087 \\
[hours/yr] & & & \\
\% of time electrical output is not fully used & $100 \%$ & $100 \%$ & $53 \%$ \\
Electricity to be purchased from utility [kWh/yr] & $\mathbf{0}$ & $\mathbf{4 4 3}$ & $\mathbf{4 4 2 , 4 8 4}$ \\
Percent of electrical demand to be purchased from utility & $\mathbf{0 \%}$ & $<\mathbf{0 . 1 \%}$ & $\mathbf{4 . 5 \%}$ \\
\hline
\end{tabular}

Table 8. Assumptions used in thermal calculations for CCHP integration

\begin{tabular}{lc}
\hline Total natural gas purchased by the plant in 2012 [MMBtu] & $\mathbf{1 9 0 , 5 6 9}$ \\
Gas cost for plant [\$/MMBtu] & 4.50 \\
Total cost of natural gas in $2012[\$]$ & $\mathbf{\$ 8 5 7 , 5 6 0}$ \\
Plant thermal energy demand considering boiler efficiency [MMBtu] & 161,983 \\
\hline Efficiency of current boiler & $85 \%$ \\
\hline Efficiency of using exhaust output & $100 \%$ \\
\hline Efficiency of using jacket water output & $100 \%$ \\
\hline Temperature of exhaust after AHP $\left({ }^{\circ} \mathrm{F}\right)$ & 250 \\
\hline
\end{tabular}


Table 9. Results for 2012 natural gas demand from CCHP integration calculations

\begin{tabular}{|c|c|c|c|}
\hline & MTU & MTU & MTU \\
\hline & GB 1941 N6 & GB 1548 N6 & GB 1149 N6 \\
\hline CHP total thermal output [MMBtu $]^{(\mathrm{a})}$ & 43,300 & 39,963 & 17,566 \\
\hline $\begin{array}{l}\text { Thermal energy to be generated by the boiler after CCHP } \\
\text { integration [MMBtu] }\end{array}$ & 118,960 & 122,265 & 144,496 \\
\hline $\begin{array}{l}\text { Natural gas to be purchased for plant processes after CCHP } \\
\text { integration [MMBtu] }\end{array}$ & 139,953 & 143,842 & 169,996 \\
\hline $\begin{array}{l}\text { Total natural gas to be purchased from utility including } \\
\text { fuel for } \mathrm{CCHP}^{(\mathrm{b})}[\mathrm{MMBtu}]\end{array}$ & 280,392 & 256,703 & 254,589 \\
\hline Percent increase in plant natural gas demand & $47 \%$ & $35 \%$ & $34 \%$ \\
\hline $\begin{array}{l}\text { (a) Less than } 1 \% \text { of the CHP thermal output is not used. } \\
\text { (b) Considering boiler efficiency of } 85 \%\end{array}$ & & & \\
\hline
\end{tabular}

Table 10. Summary of cost savings with the integration of CCHP

\begin{tabular}{|c|c|c|c|}
\hline & MTU & MTU & MTU \\
\hline & GB 1941 N6 & GB 1548 N6 & GB 1149 N6 \\
\hline CHP total electrical output (assuming $24 \times 7 \times 366$ ) [kWh] & $17,049,744$ & $13,597,632$ & $10,092,816$ \\
\hline Electricity to be purchased from utility [kWh/yr] & 0 & 443 & 442,484 \\
\hline Cost of electricity to be purchased from utility [\$/yr] & $\$ 0$ & $\$ 40$ & $\$ 39,492$ \\
\hline $\begin{array}{l}\text { Reduction in cost of electricity to be purchased from } \\
\text { utility after CCHP }[\$ / y r]\end{array}$ & $\$ 1,333,644$ & $\$ 1,333,604$ & $\$ 1,294,152$ \\
\hline $\begin{array}{l}\text { Reduction in natural gas demand for plant processes after } \\
\text { CCHP [MMBtu/yr] }\end{array}$ & 50,616 & 46,727 & 20,573 \\
\hline Reduction in natural gas cost for plant processes [ $\$ / \mathrm{yr}]$ & $\$ 227,771$ & $\$ 210,273$ & $\$ 92,579$ \\
\hline Cost of CCHP generation assuming $0.067 \$ / \mathrm{kWh}$ [ $\$ /$ year] & $\$ 1,159,383$ & $\$ 911,041$ & $\$ 676,219$ \\
\hline $\begin{array}{l}\text { Amount saved in plant electric and gas costs by CCHP } \\
\text { [\$/year] }\end{array}$ & $\$ 402,032$ & $\$ 632,836$ & $\$ 710,512$ \\
\hline
\end{tabular}




\subsection{Feasibility Analysis}

\subsection{Energy Assessment}

Selecting CHP system model MTU GB 1149 (1.1 MW capacity) requires 442 MWh of electricity to be purchased from the utility, while selecting CHP system model MTU GB 1941 (1.9 MW capacity) fully supports the plant electrical demand. Figure 33 illustrates electricity demand from the plant, the amount supplied by CCHP, and the amount of electricity that needs to be purchased from the utility when GB 1149 (1.1 MW capacity) is selected (Table 11). Figure 34 and Table 12 shows gas demand with CCHP.

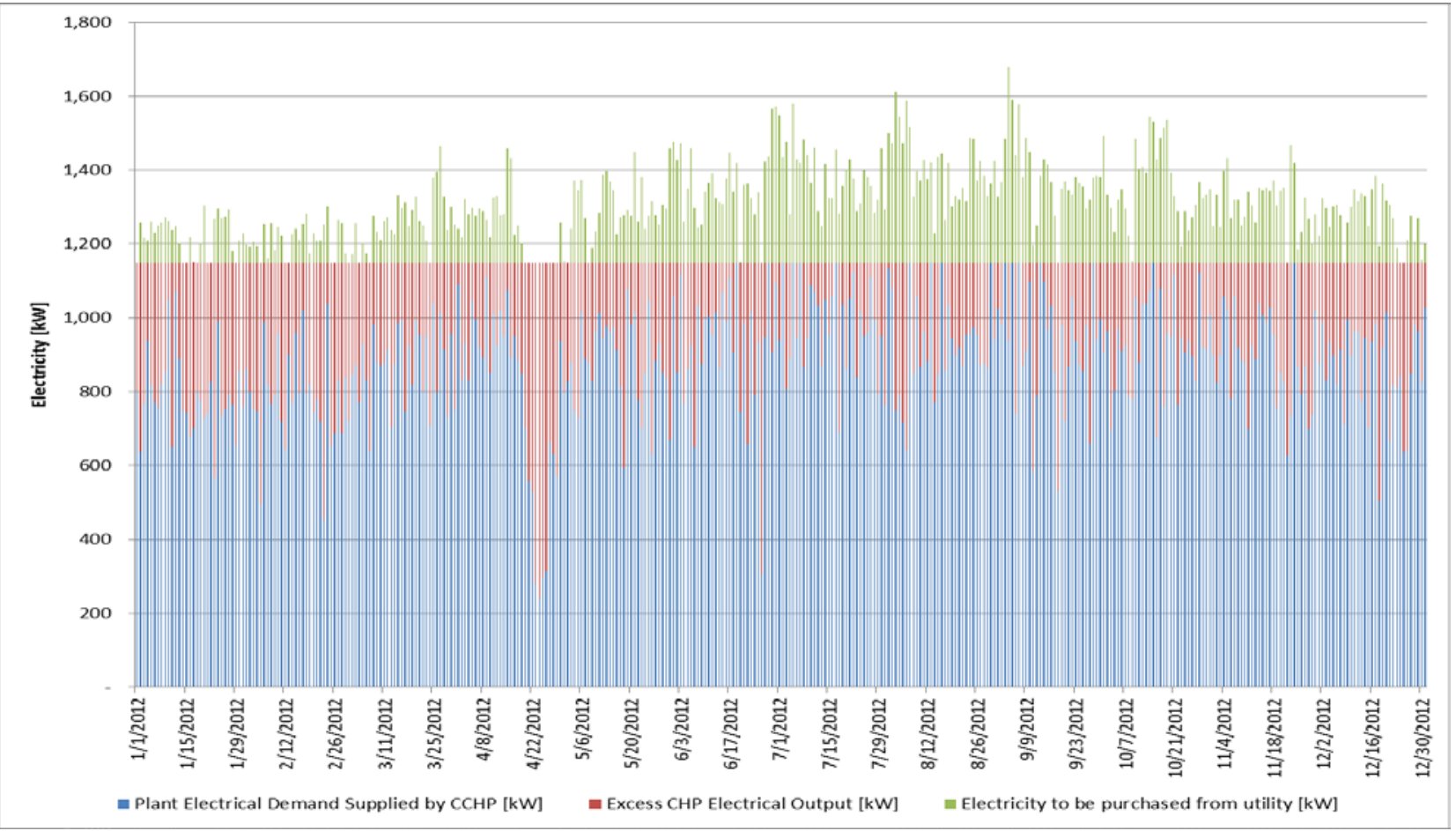

Figure 33. Plant electrical demand supplied by CCHP, amount not used, and amount to be purchased from utility when Model GB 1149 is chosen

Table 11. Summary table - electricity demand before and after CCHP

\begin{tabular}{lccc}
\hline & MTU & MTU & MTU \\
\cline { 2 - 4 } & GB 1941 N6 & GB 1548 N6 & GB 1149 N6 \\
\hline Electricity demand of the plant before CCHP [kWh/yr] & & $14,942,788$ & \\
Electricity to be purchased from utility after CCHP [kWh/yr] & 0 & 443 & 442,484 \\
Amount of electricity offset by CCHP [kWh/yr] & $\mathbf{1 4 , 9 4 2 , 7 8 8}$ & $\mathbf{1 4 , 9 4 2 , 3 4 5}$ & $\mathbf{1 4 , 5 0 0 , 3 0 4}$ \\
\hline
\end{tabular}




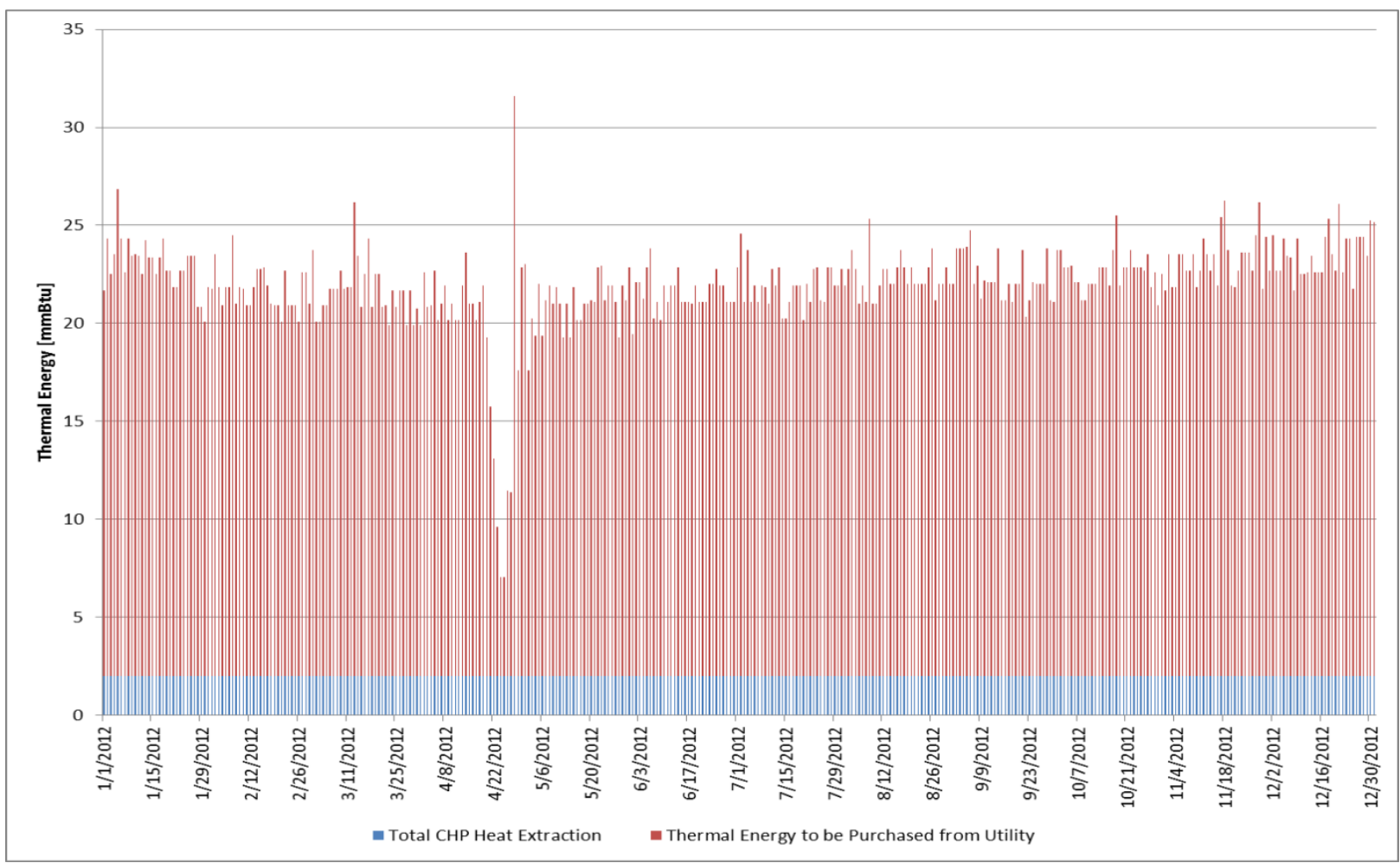

Figure 34. Thermal energy supplied by the CCHP and amount to be purchased from the utility when Model GB 1149 is chosen

Table 12. Summary table - natural gas demand before and after CCHP

\begin{tabular}{lccc}
\hline & MTU & MTU & MTU \\
\cline { 2 - 4 } & GB 1941 N6 & GB 1548 N6 & GB 1149 N6 \\
\hline Gas demand of the plant before CCHP [MMBtu/yr] & & 190,569 \\
Gas to be purchased from utility after CCHP [MMBtu/yr] & 280,392 & 256,703 & 254,589 \\
Increase in gas requirement with CCHP [MMBtu/yr] & $\mathbf{8 9 , 8 2 4}$ & $\mathbf{6 6 , 1 3 4}$ & $\mathbf{6 4 , 0 2 0}$ \\
\hline
\end{tabular}




\subsection{Economic Assessment}

Net savings are calculated in Table 3 below. Outages are considered at a cost of $\$ 15,000$ per incident as reported by engineers at the plant. Results indicate that CHP system model MTU GB 1149 provides maximum net savings with and without considering cost of outages. It should be noted that from Table 7 this unit can supply the plant's entire electrical demand 53\% of the time. In addition, Table 7 shows that this unit does not provide $4.5 \%$ of the electricity required by the plant. However here in Table 13, we are assuming the CCHP unit can still supply all critical equipment electricity demand during power outages.

Table 13. Summary of economic evaluation for CCHP system selection

\begin{tabular}{|c|c|c|c|}
\hline & MTU & MTU & MTU \\
\hline & GB 1941 N6 & GB 1548 N6 & GB 1149 N6 \\
\hline Cost of electricity purchased from utility before CCHP [\$/yr] & & $\$ 1,333,644$ & \\
\hline Cost of natural gas purchased before CCHP [\$/yr] & & $\$ 857,560$ & \\
\hline Total fuel cost before CCHP [\$/yr] & & $\$ 2,191,204$ & \\
\hline Total cost of fuel after CCHP & $\$ 1,789,172$ & $\$ 1,558,369$ & $\$ 1,480,694$ \\
\hline Annual net savings $[\$ / y r]$ & $\$ 402,032$ & $\$ 632,836$ & $\$ 710,512$ \\
\hline $\begin{array}{l}\text { Estimated cost of outages assuming outage cost of } \$ 15 \mathrm{~K} \text { per } \\
\text { incident }[\$ / \mathrm{yr}]\end{array}$ & $\$ 420,000$ & $\$ 420,000$ & $\$ 420,000$ \\
\hline $\begin{array}{l}\text { Net annual savings assuming outage cost of } \$ 15 \mathrm{~K} \text { per } \\
\text { incident }[\$ / \mathrm{yr}]\end{array}$ & $\$ 822,032$ & $\$ 1,052,837$ & $\$ 1,130,514$ \\
\hline $\begin{array}{l}\text { Estimated cost of delivered system. Includes capital cost for } \\
\text { engine driven generator, AHP, and energy storage device. } \\
\text { Installation costs are not included. }\end{array}$ & $\$ 2,422,975$ & $\$ 2,380,096$ & $\$ 2,013,137$ \\
\hline Estimated average savings in 10 years & $\$ 5,797,345$ & $\$ 8,148,274$ & $\$ 9,292,003$ \\
\hline
\end{tabular}




\subsection{Environmental Assessment}

Fuels used in the Northwest for power generation (Figure 35) are used to calculate the amount of emissions generated to supply Plant \#1. Emissions are calculated using amounts of emissions for electricity generation from the Environmental Protection Agency (EPA) ${ }^{8}$ and tabulated in Table 4.

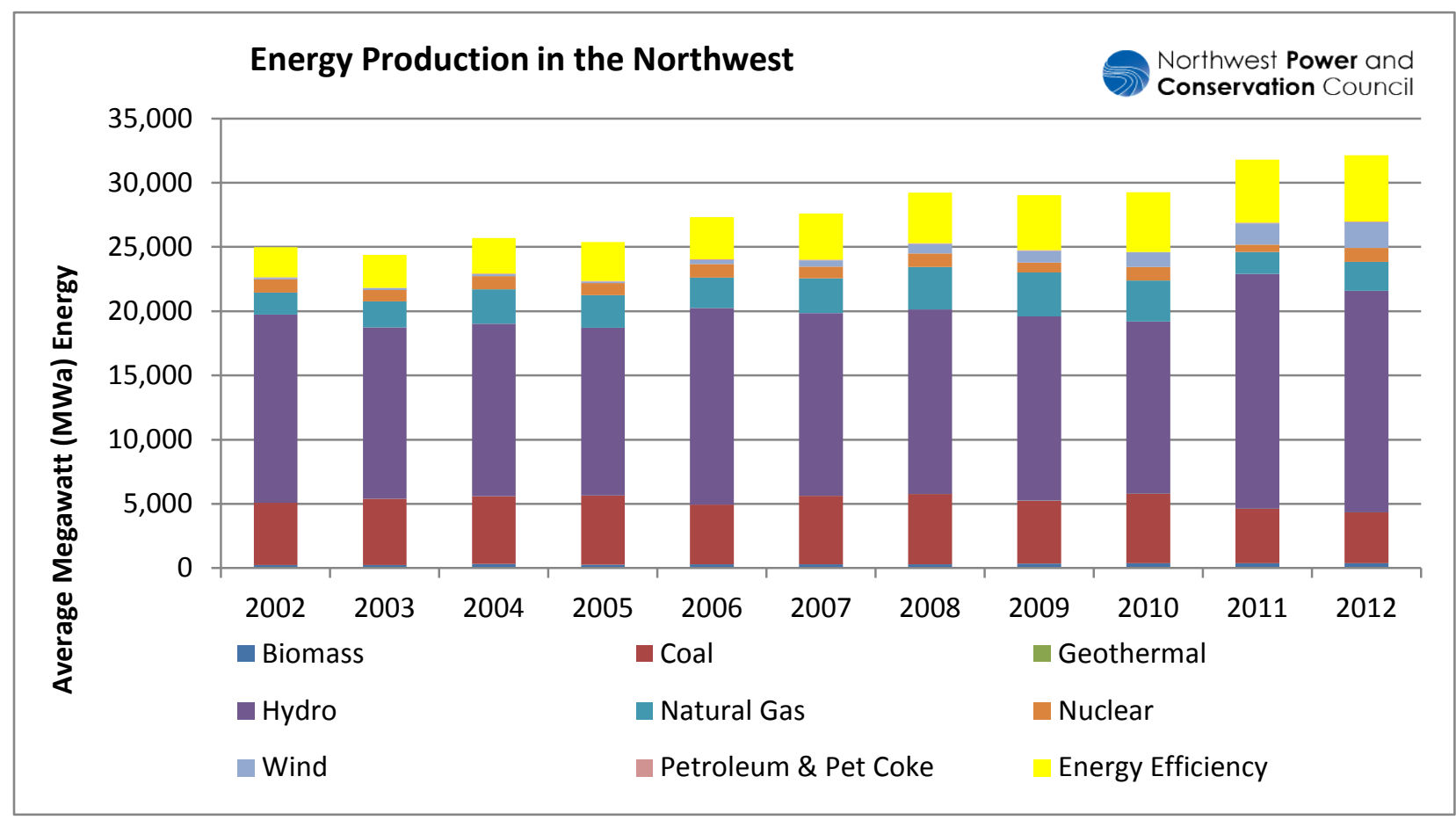

Figure 35. Fuels used for power generation in the Northwest (Source: Northwest Power and Conservation Council)

Table 14. Type of fuels used in the Northwest to generate power and emissions per unit of those fuels

\begin{tabular}{lccccc}
\hline $\begin{array}{c}\text { Fuel Used in } \\
\text { NW to Generate } \\
\text { Electricity }\end{array}$ & $\begin{array}{c}\text { Amount of Fuel } \\
\text { [MWa] }\end{array}$ & $\begin{array}{c}\text { Fraction of Fuel } \\
\text { Used in NW }\end{array}$ & $\begin{array}{c}\text { Nitrogen Oxide } \\
\text { Emissions } \\
\text { [lbs/MWh] }\end{array}$ & $\begin{array}{c}\text { Carbon Dioxide } \\
\text { Emissions } \\
\text { [lbs/MWh] }\end{array}$ & $\begin{array}{c}\text { Sulfur Dioxide } \\
\text { Emissions } \\
\text { [lbs/MWh] }\end{array}$ \\
\hline Natural Gas & 2245 & $7.0 \%$ & 1.7 & 1135 & 0.1 \\
Coal & 3945 & $12.3 \%$ & 6 & 2249 & 13 \\
Hydro & 17,256 & $53.7 \%$ & N/A & N/A & N/A \\
Biomass & 384 & $1.2 \%$ & 6.7 & 3685 & 1.2 \\
Petroleum & 46 & $0.1 \%$ & 4 & 1672 & 12 \\
Wind & 2007 & $6.2 \%$ & N/A & N/A & N/A \\
Other & 6247 & $19.4 \%$ & N/A & N/A & N/A \\
\hline
\end{tabular}

${ }^{8}$ Available at http://www.epa.gov/cleanenergy/energy-and-you/affect/air-emissions.html 
Fractions of fuel used by Portland General Electric (PGE) to supply electricity needs of its consumers are different from those for the fuel used in the entire Northwest. Figure 36 shows PGE's 2012 resource mix.

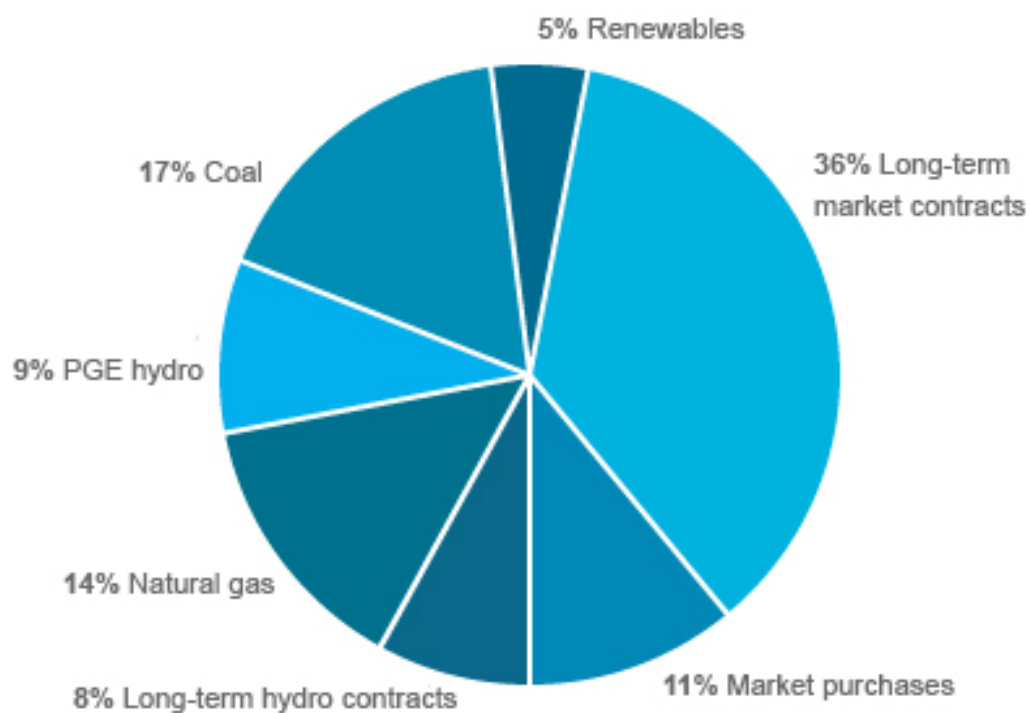

Figure 36. PGE 2012 resource mix (Source: PGE $^{9}$ )

Using the resource mix shown in Figure 36, the amount of emissions generated to supply electrical demand for Plant \#1 is calculated as shown in Table 5.

Table 15. Power system emissions to supply Plant \#1

\begin{tabular}{lcccc}
\hline & $\begin{array}{c}\text { Amount of Each Fuel Used } \\
\text { to Generate Electricity } \\
\text { Consumed by Plant\#1 } \\
{[\mathrm{MWh}]}\end{array}$ & $\begin{array}{c}\text { Nitrogen Oxide } \\
\text { Emissions } \\
{[\mathrm{lbs}]}\end{array}$ & $\begin{array}{c}\text { Carbon Dioxide } \\
\text { Emissions } \\
{[\mathrm{lbs}]}\end{array}$ & $\begin{array}{c}\text { Sulfur Dioxide } \\
\text { Emissions } \\
{[\mathrm{lbs}]}\end{array}$ \\
\hline Natural Gas & $2,091.99$ & 3.56 & $2,374.41$ & 0.21 \\
Coal & $2,540.27$ & 15.24 & $5,713.08$ & 33.02 \\
Biomass & - & - & - & - \\
Petroleum & 21.39 & 0.09 & 35.77 & 0.26 \\
Wind & 747.14 & - & - & - \\
Hydro & $2,540.27$ & - & - & - \\
\hline Total & & $\mathbf{1 8 . 8 8}$ & $\mathbf{8 , 1 2 3 . 2 5}$ & $\mathbf{3 3 . 4 9}$ \\
\hline
\end{tabular}

The amount of emissions produced by losses in T\&D lines can be calculated assuming it can be quantified using the amount of electricity rejected. However, these are not considered in this calculation, but it should be noted that rejected energy in electricity generation in the Northwest is close to $63 \%$ of

\footnotetext{
${ }^{9}$ https://www.portlandgeneral.com/our_company/corporate_info/how_we_generate_energy.aspx
} 
total electricity generated in the region (this includes losses as a result of low efficiency of generators). By taking into account the losses in T\&D lines, the figures shown in Table will increase.

Amounts of emissions per unit of electricity are available from EPA: ${ }^{10}$ nitrogen oxides generate $0.0751 \mathrm{lbs} / \mathrm{MWh}$, carbon dioxide generates $1056 \mathrm{lbs} / \mathrm{MWh}$, and sulfur oxides generate 0.0376 lbs/MWh of emissions. If it is assumed that the plant's entire electrical demand is supplied by natural gas CCHP, then emissions after CCHP integration will be as shown in Table 6.

Table 16. Amounts of emissions before and after CCHP assuming all electricity needs of the plant are satisfied by the CCHP

\begin{tabular}{lccc}
\hline & Nitrogen Oxide & Carbon Dioxide & Sulfur Dioxide \\
& {$[\mathrm{lbs}]$} & {$[\mathrm{lbs}]$} & 33.49 \\
\hline Emissions before CCHP & 18.88 & $8,123.25$ & 1.49 \\
Emissions with CCHP & 1.12 & $15,779.58$ & $-95.54 \%$ \\
\hline \% change in emissions & $-94.06 \%$ & $94.25 \%$ & \\
\hline
\end{tabular}

The $\mathrm{CO}_{2}$ is increased because of the high ratio of hydro power in the Northwest region (hidden in Figure 36, since breakdown of long-term market contracts and market purchases are not specified). Yet, if we assume PGE is purchasing their extra power needs (under market purchases and market contracts) from other resources in the Northwest, then we can use the values shown in Table to recalculate emissions (assuming 47\% of power has the same distribution of fuel as shown in Table as 'Ratios of fuel used in NW'. Doing that will reduce carbon dioxide emissions after CCHP integrations to a 48.19\% increase instead of the $94.25 \%$ currently shown.

${ }^{10}$ http://www.epa.gov/chp/documents/datactr_whitepaper.pdf 


\subsection{Conclusion}

Results from the energy and economic assessment indicate that CHP system model MTU GB 1149 N6 with a capacity of $1,149 \mathrm{~kW}$ is the system that maximizes benefits for the plant. This system has a capital cost of $\$ 2,013,137$ and is expected to yield annual savings of $\$ 1,130,514$ (including savings from costs of outages for the plant). Longer term savings can be observed with the assumption that natural gas prices do not increase. However, the benefits of integrated CCHP are not limited to energy and economic savings. Reduction in emissions is another strong motive to invest in CCHP. It is not easy to quantify or monetize the impact of implementing CCHP in terms of emissions; however, in the case of Plant \#1, calculations showed that reduction in emissions was noteworthy.

To enhance power reliability, the plant management can consider investing in an ESS. One $250 \mathrm{~kW}$ system costs around $\$ 160,000$ (plus installation costs) and can support the plant electricity demand that needs to be protected from power outages. Considering the cost of storage, the simple payback would still be less than two years. ${ }^{11}$ Given that with the proposed 1.1 MW CCHP system the maximum electric demand from the utility is estimated to be $500 \mathrm{~kW}$, integrating two $250 \mathrm{~kW}$ systems will allow a more sophisticated system that has the potential to reduce electricity demand peaks. However, analyzing such a system is beyond the scope of this current study.

Penetration of DG is among non-wires solutions considered by BPA to address load growth and congestion on the transmission system. This solution will help maintain power reliability for food processing plants. In the case of Plant 1, integration of 1.1 MW CCHP results in shifting 9,271 MWh of electricity off the grid and thereby reducing congestion on the transmission system. During peak time (which is an annual peak rather than a daily peak), the plant still needs to purchase about 400-550 kW from the grid $0.16 \%$ of the year; a fraction of the electricity needed by the plant during the peak time. In 2012, this was $30 \%$ of the electricity needed at the highest peak.

The highest probability of the benefits being realized is in end-of-life equipment replacement or retrofits, until BPA customers' loads recover and drive Tier 2 rate risk or have the need to reduce demand charges coincident with BPA peak (end use vs. distribution utility vs. BPA demand peak).

\footnotetext{
${ }^{11}$ It should be noted that the service life of the CCHP and ESS is not considered in this study.
} 


\subsection{References}

Bonneville Power Administration (BPA). 2012. Northwest Energy Efficiency Technology Roadmaps Series: Food Processing. Accessed March 3, 2014 at http://www.bpa.gov/corporate/business/innovation/docs/2012/NW EE_Industrial Tech RM Food_Proc essing_March_2012.pdf

Brush A, E Masanet, and E Worrell. 2011.Energy Efficiency Improvement and Cost Saving Opportunities for the Dairy Processing Industry, an ENERGY STAR ${ }^{\circledR}$ Guide for Energy and Plant Managers. Lawrence Berkeley National Laboratory, Berkeley, CA. 